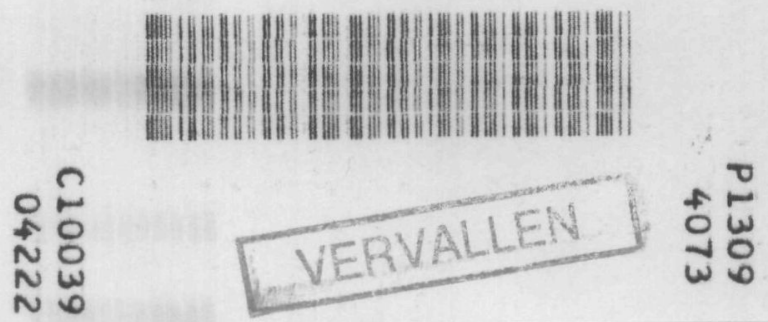

BIBLIOTHEEK TU Delft

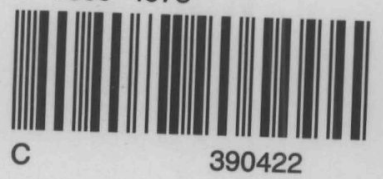



HIGH-FREQUENCY SCATTERING BY A CONVEX SMOOTH OBJECT 


\title{
HIGH-FREQUENCY SCATTERING BY A CONVEX SMOOTH OBJECT
}

\author{
PROEFSCHRIFT \\ TER VERKRIJGING VAN DE GRAAD VAN DOCTOR \\ IN DE TECHNISCHE WETENSCHAPPEN AAN DE \\ TECHNISCHE HOGESCHOOL DELFT, OP GEZAG \\ VAN DE RECTOR MAGNIFICUS DR. IR. C. J. D. M. \\ VERHAGEN, HOOGLERAAR IN DE AFDELING \\ DER TECHNISCHE NATUURKUNDE, VOOR EEN \\ COMMISSIE UIT DE SENAAT TE VERDEDIGEN \\ OP WOENSDAG 9 OKTOBER 1968 TE 16 UUR \\ DOOR

\section{ADRIANUS JURIANUS HERMANS} \\ wiskundig ingenieur \\ geboren te Leiden
}

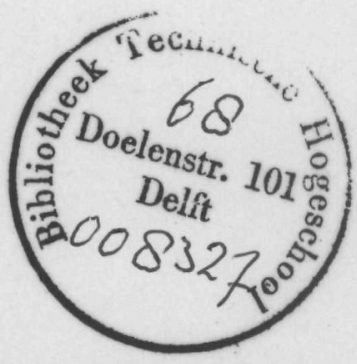

UITGEVERIJ WALTMAN - DELFT

\section{3}


DIT PROEFSCHRIFT IS GOEDGEKEURD DOOR DE PROMOTOR PROF. DR. R. TIMMAN.

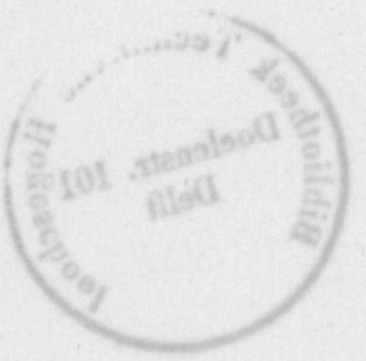


Aan mijn ouders en Rientje 


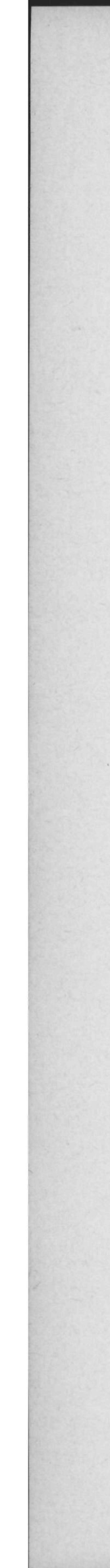




\section{CONTENTS}

Introduction . . . . . . . . . . . . . . . . . . . 9

CHAPTER I SCATTERING OF A PLANE WAVE BY A SPHERE

1 Formulation. . . . . . . . . . . . . 11

2 Asymptotic expansion of the diffracted wave. . . . . . . 14

3 Boundary layer expansion near the sphere and the shadow boundary . . . . . . . . . . . . . 18

4 Asymptotic expansion near the sphere at finite distance from the shadow boundary. . . . . . . . . . . . . 22

5 Asymptotic expansion at finite distance to the sphere . . . 25

6 Asymptotic expansion near the axis of symmetry . . . . . . 25

7 Final asymptotic solution in the shadow region . . . . . . 29

8 Asymptotic behaviour in the lit region ........ . 34

CHAPTER II SCATTERING OF A SPHERICAL WAVE BY A SPHERE

9 Asymptotic expansion in the shadow region . . . . . . . . 35

10 Asymptotic expansion in the lit region . . . . . . . . 45

CHAPTER III DIFFRACTION OF WAVES BY AN ARBITRARY SMOOTH CONVEX OBJECT

11 Derivation of the asymptotic equation ....... 46

12 The incident wave is plane .......... . . . 50

13 The incident wave is spherical . . . . . . . . . . 54

CHAPTER IV EXAMPLES

14 Circular cylinder with plane incident wave. . . . . . . . 57

15 Circular cylinder with spherical incident wave . . . . . . 60

Appendix ..................... 65

References ................. . . . . 69

Samenvatting ....................... 71 


\section{CONTENTS}

Introduction . . . . . . . . . . . . . . . 9

CHAPTER I SCATTERING OF A PLANE WAVE BY A SPHERE

1 Formulation. . . . . . . . . . . . . 11

2 Asymptotic expansion of the diffracted wave. . . . . . . . 14

3 Boundary layer expansion near the sphere and the shadow boundary . . . . . . . . . . . . 18

4 Asymptotic expansion near the sphere at finite distance from the shadow boundary. . . . . . . . . . . 22

5 Asymptotic expansion at finite distance to the sphere . . . . 25

6 Asymptotic expansion near the axis of symmetry . . . . . . 25

7 Final asymptotic solution in the shadow region . . . . . . 29

8 Asymptotic behaviour in the lit region . . . . . . . . . 34

CHAPTER II SCATTERING OF A SPHERICAL WAVE BY A SPHERE

9 Asymptotic expansion in the shadow region . . . . . . . . 35

10 Asymptotic expansion in the lit region . . . . . . . . 45

CHAPTER III DIFFRACTION OF WAVES BY AN ARBITRARY SMOOTH CONVEX OBJECT

11 Derivation of the asymptotic equation . . . . . . . 46

12 The incident wave is plane ... . . . . . . 50

13 The incident wave is spherical . . . . . . . . . . . 54

CHAPTER IV EXAMPLES

14 Circular cylinder with plane incident wave . . . . . . . . 57

15 Circular cylinder with spherical incident wave . . . . . . 60

Appendix . . . . . . . . . . . . . . 65

References ................... . . . 69

Samenvatting ...................... 71 



\title{
INTRODUCTION
}

\author{
HISTORICAL
}

The problem to be treated is the three-dimensional scattering of a scalar wave, by a totally reflecting smooth convex object, at high frequencies.

In this thesis we apply the ray method of J. B. KeLLER [6-11] to solve this problem. This method, based on the ray-concept, is combined with the method of boundarylayer expansions. The reasoning being essentially physical in nature makes these methods more advantageous in comparison with other methods. Although exact proofs are not available, the correctness of this theory is not seriously questioned and it is believed that it yields asymptotic representations, valid for short wavelength, of exact solutions of the Helmholtz equation. The evidence for this comes from exact solutions, valid for a few simple geometrical configurations, e.g. the two-dimensional circular cylinder and the sphere, for which short-wave expansions can be found rigorously. A disadvantage of the treatment given by J. B. KelLer [6-11] and E. ZAUDERER [12] a.o. is that in order to find asymptotic solutions these authors always use results which are obtained by other methods, such as results of the treatment of the exact solution by means of the Watson transformation. The aim of the author is to derive systematically asymptotic solutions of the Helmholtz equation, by means of the ray method and boundary layer expansions, without using any result obtained by other methods. Asymptotic results are derived by solving asymptotic equations, which have different forms in different regions, with boundary conditions, on the object and at infinity and matching conditions which follow from results, obtained in neighbouring regions.

V. A. Fock [16] in his two-dimensional treatment of short-wave diffraction by a convex cylinder used the ray method and boundary-layer expansions as well.

A very extensive treatment of the asymptotic solution of the Helmholtz equation has recently been given by H. M. NusSENZVEIG [1]. He worked out the problem of diffraction of a plane wave by a sphere, for large values of frequency, starting with the known exact solution. NuSSENZVEIG reformulated Watson's transformation and gave expansions for high frequencies in the whole space.

An imitation of this treatment has been developed by D. LuDwIG [3], which yields the asymptotic solution in the space around a smooth convex object of arbitrary shape. However, it is a purely mathematical treatment without physical backgrounds and in the author's opinion the ray theory is preferable. 
Recently a method of tackling the asymptotic solution of diffraction problems has been proposed by D. S. JoNES $[4,5]$. He considered the problem of the diffraction of a wave at high frequencies by a circular disc. To solve this problem he derived an integral equation and found some asymptotic solutions.

His method is applicable, in principle, to the diffraction problems which we will consider here. However, it is not easy to solve the integral equation which arises in the three-dimensional scattering problem. We therefore apply the ray theory.

\section{INTRODUCTION TO THE PROBLEM}

As mentioned before, the problem of scattering of a scalar wave by a totally reflecting smooth object at high frequencies will be considered. Hence we are interested in solutions of the Helmholtz equation

$$
\Delta \tilde{\varphi}+k^{2} \tilde{\varphi}=0
$$

with $(k a) \gg 1$ where a is a measure for the radius of curvature of the object. In the subsequent sections it seems that we even should take $(k a)^{\frac{1}{3}} \gg 1$. The boundary condition on the object is $\tilde{\varphi}=0$.

The wave function $\tilde{\varphi}$ can be interpreted either as the velocity potential of sound waves corresponding to an acoustically soft object, or as the Schrödinger wave function, in nonrelativistic quantum mechanics [18], in which case it corresponds to a hard-core potential. The theory of material waves leads unambiguously to the wave equation

$$
i \hbar \frac{\partial \psi}{\partial t}=-\frac{\hbar^{2}}{2 m} \Delta \psi+U(x, y, z) \psi
$$

with $U(x, y, z)$ as the potential energy of the particle in the external field.

We consider the stationary case and with $E=p^{2} / 2 m$ the equation becomes

$$
\frac{\hbar^{2}}{2 m} \Delta \tilde{\varphi}+\{E-U(x, y, z)\} \tilde{\varphi}=0 .
$$

Hence for the movement of a free particle we arrive at the Helmholtz equation

$$
\Delta \tilde{\varphi}+k^{2} \tilde{\varphi}=0
$$

where $k^{2}=E \cdot\left(2 m / \hbar^{2}\right)$.

The object we are dealing with is impenetrable, hence we have $\tilde{\varphi}=0$ as a boundary condition.

There is no difficulty in extending the treatment to a vector wave field, so as to represent electromagnetic scattering from a perfectly conducting object in a homogeneous medium. 


\section{SCATTERING OF A PLANE WAVE BY A SPHERE}

\section{FORMULATION}

The scattering of a scalar plane wave by a totally reflecting smooth object in a homogeneous medium will be treated here. We are interested in the asymptotic behaviour of the wave function for large values of the frequency. The scalar function $\tilde{\varphi}$ has to be a solution of the three-dimensional wave equation

$$
\Delta \tilde{\varphi}+k^{2} \tilde{\varphi}=0
$$

especially with large values of $k(k a \gg 1)$.

This function $\tilde{\varphi}$ must be equal to zero on the surface of the object and satisfy the radiation condition at infinity. This condition will be considered in the following section.

In the first place we will consider the diffraction of a plane wave by a sphere with unit radius and its centre in the origin of the $x y z$ space. The plane wave has the form

$$
\tilde{\varphi}_{\text {inc }}=e^{i k x}
$$

If the constant $k$ is large $(k \gg 1)$, we can use the 'ray' theory to find an asymptotic solution of the problem. Therefore we have to define rays first.

Rays are introduced by means of the following substitution

$$
\tilde{\varphi}(\mathbf{x}, k)=\varphi(\mathbf{x}, k) e^{i k S(\mathbf{x})}
$$

in which $\mathbf{x}=(x, y, z)$.

If we insert $(1,2)$ in $(1,1)$, we obtain

$$
\Delta \varphi+i k(2 \nabla \varphi \cdot \nabla S+\varphi \Delta S)+k^{2}\left[1-(\nabla S)^{2}\right] \varphi=0 .
$$

If $\varphi$ and $S$ do not have large gradients, then for large values of $k$ the $k^{2}$ term is the leading one. Hence we put its coefficient equal to zero and we get

$$
(\nabla S)^{2}=1
$$

In geometrical optics this equation is the well-known eiconal equation. Its characteristics are straight lines which are perpendicular to surfaces $S=$ constant. 


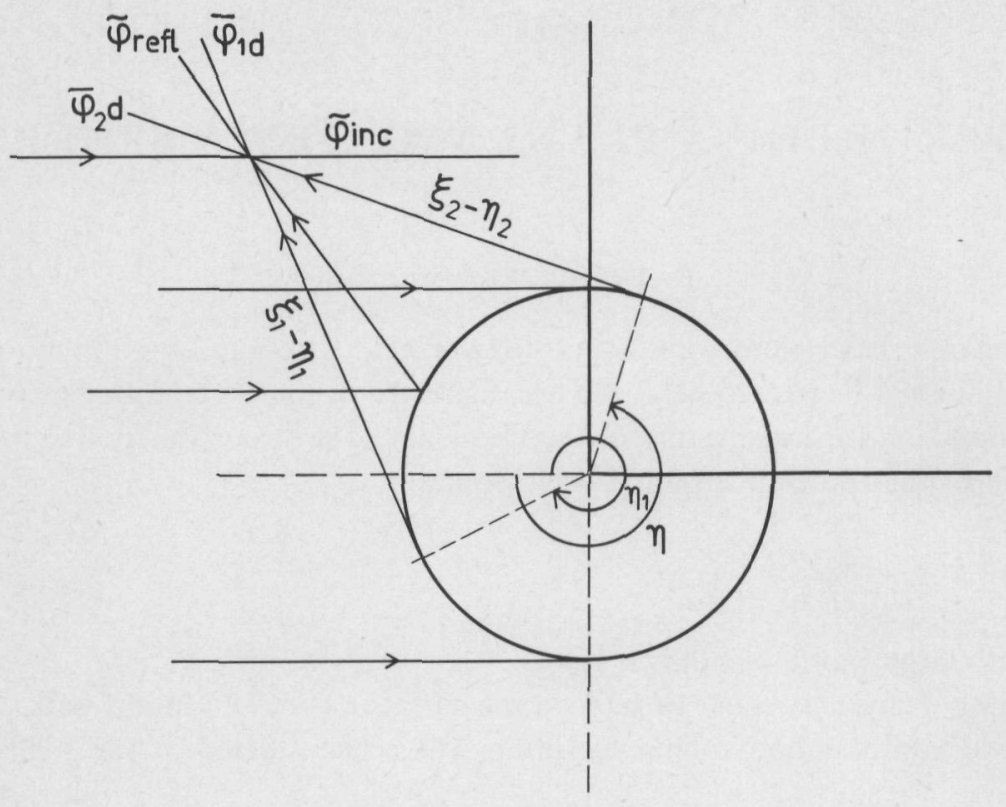

Fig. 1a

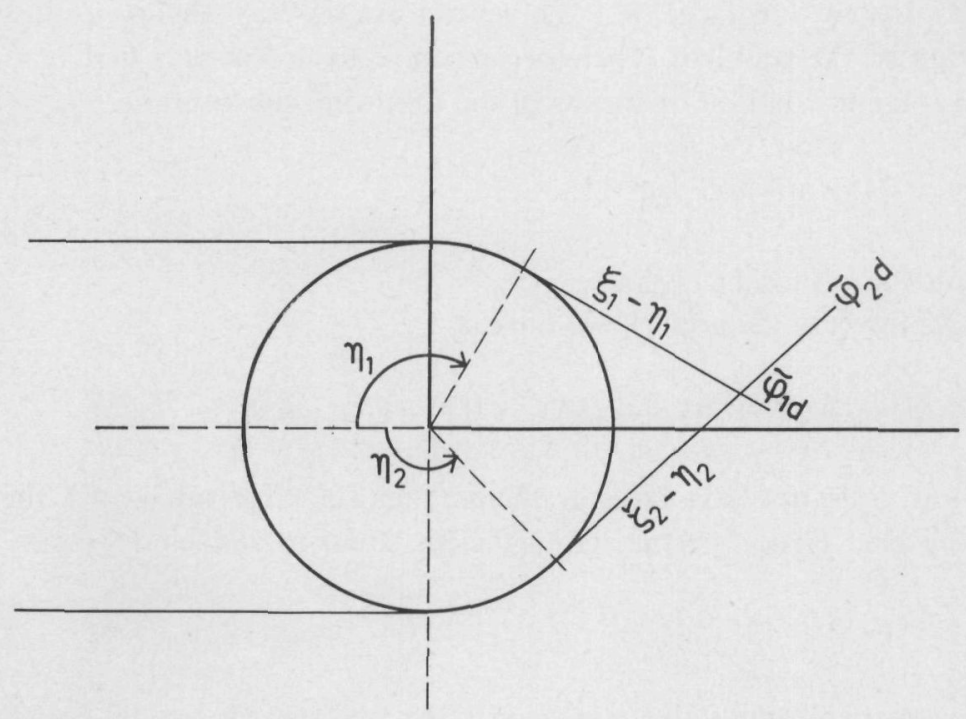

Fig. 1b 
If we introduce the arclength $\xi$ along these characteristics and choose $\xi$ positively in the direction of increasing $S$, then we get along these lines

$$
S=S_{o}+\xi
$$

where $S_{0}$ is an integration constant.

We call these characteristics rays.

In geometrical optics rays are often introduced by means of the Fermat principle. In general we can easily verify [19] that in a nonhomogeneous medium the characteristics of the equation

$$
(\nabla S)^{2}=n^{2}(\mathbf{x})
$$

in which $n(\mathbf{x})$ is the refractive index, (we arrive at this eiconal equation, if we put in equation $(1,1) k^{2} n^{2}(\mathbf{x})$ instead of $k^{2}$ ) are the curves between two fixed points $\mathbf{x}_{1}$ and $\mathbf{x}_{2}$ along which the optical path length

$$
\int_{C} n(\mathbf{x}) \mathrm{d} S
$$

is stationary with respect to small variations in the integration path $C$.

The case in question deals with a homogeneous medium with $n(\mathbf{x})=1$, so the rays are straight lines.

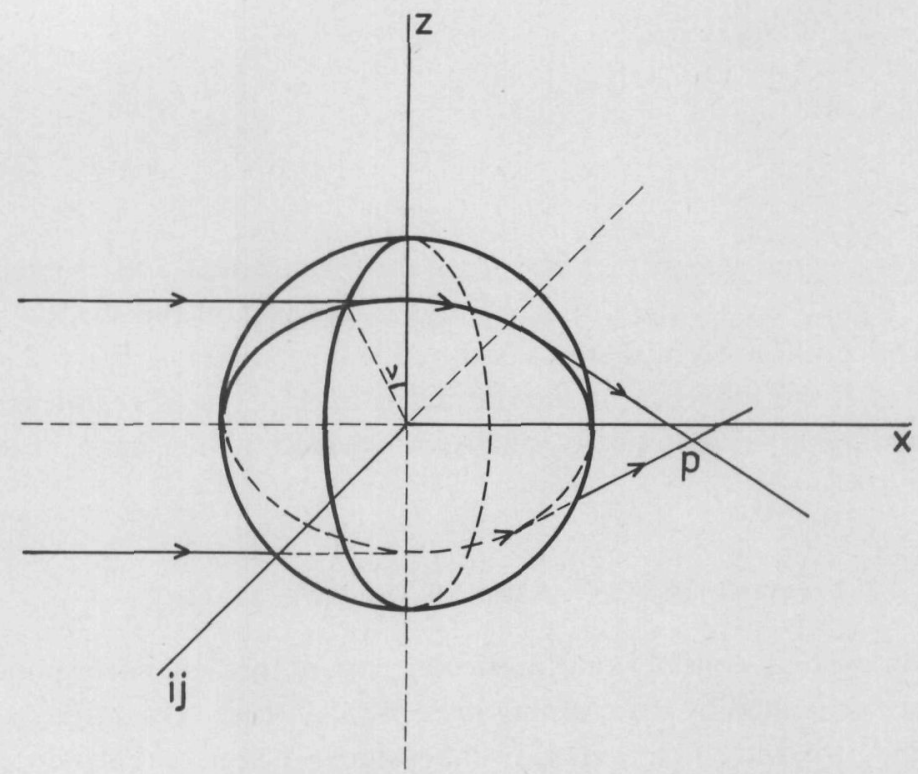

Fig. 1c 
The incoming rays of our problem are rays parallel to the $x$-axis with unit amplitude. If we put the sphere in this field, we find two different regions, viz. a lit region and a shadow region. In the lit region every point is reached by two rays, a direct incoming ray and a ray reflected by the sphere. In this way no rays will come into the shadow region. Hence we are dealing with a solution of $(1,1)$ which is discontinuous along the shadow boundary and the assumption that the gradients are moderate, is violated, so the $k^{2}$ term is not the leading one anymore. If we still require solutions of the form $(1,2)$, we must remove the discontinuity.

We therefore define creeping rays [14].

Creeping rays are rays generated by that part of the incoming rays which meets the surface tangentially and follows the geodesics of the object in a direction which is the same as the incoming rays. Each point of these geodesics will generate a ray into free space tangentially to the geodesic line with a certain amplitude.

In the case discussed here the geodesics are circles in flat planes through the $x$-axis. As we see the geodesics of the sphere are closed curves and considering a geodesic in a certain plane, we observe that a point $\mathbf{P}$ of that plane is reached by an infinite set of rays, because the creeping rays circle round the geodesic many times. We also see that each geodesic is a line of creeping rays generated by two incident rays (Fig. 1b). Hence a point $P$ is reached by two infinite sets of rays and if $P$ lies on the $x$-axis a cone of rays will reach this point, therefore special attention must be given to the $x$-axis.

These geometrical considerations yield the solution

$$
\tilde{\varphi}=\tilde{\varphi}_{\mathrm{inc}}+\tilde{\varphi}_{\mathrm{refl}}+\bar{\varphi}_{d}
$$

in the lit region and

$$
\tilde{\varphi}=\tilde{\varphi}_{d}
$$

in the shadow region, where $\tilde{\varphi}_{\text {inc }}$ and $\tilde{\varphi}_{\text {refl }}$ are the incident and the reflected ray, respectively. $\bar{\varphi}_{d}$ and $\tilde{\varphi}_{d}$ are the diffracted rays in the lit and the shadow region, respectively. These diffracted rays are caused by the creeping rays. We will see that for large values of $k$ the influence of the diffracted rays in the lit region far from the shadow boundary is asymptotically small with respect to the incident and the reflected ray.

\section{ASYMPTOTIC EXPANSION OF THE DIFFRACTED WAVE}

In this section we only consider that particular part of the field corresponding to the rays which are generated by the creeping rays. We call these rays diffracted rays.

To determine the wave function $\tilde{\varphi}_{d}$ in the shadow region, we introduce new variables $\xi, \eta$ and $v$ as shown in Fig. 1a, b, where 
$\xi-\eta$ is the arclength along the ray after leaving the sphere;

$\eta-\frac{1}{2} \pi$ is the arclength along the creeping ray;

$v$ is the polar angle.

As a point is reached by two sets of different rays, we should consider that the coordinates are not single-valued. The rays at a point are determined by

$$
\begin{aligned}
\xi_{m l} & =\xi_{l}+2 \pi m, \\
\eta_{m l} & =\eta_{l}+2 \pi m, \\
v_{l} & =v+\pi l
\end{aligned}
$$

where

$$
\begin{aligned}
& 0<\eta_{l} \leqq 2 \pi, \\
& m=1,2,3, \ldots, \\
& 0<v \leqq \pi \\
& l=1,2 .
\end{aligned}
$$

If we summarize the contributions of all these rays, we get the total wave function in a point $(x, y, z)$

$$
\tilde{\varphi}(x, y, z)=\sum_{m=0}^{\infty} \tilde{\varphi}\left(\xi_{m 1}, \eta_{m 1}, v_{1}\right)+\sum_{m=0}^{\infty} \tilde{\varphi}\left(\xi_{m 2}, \eta_{m 2}, v_{2}\right)
$$

It is evident that in the new coordinates the line element $\mathrm{d} s$ becomes

$$
\mathrm{d} s^{2}=\mathrm{d} \xi^{2}+(\xi-\eta)^{2} \mathrm{~d} \eta^{2}+\{\sin \eta+(\xi-\eta) \cos \eta\}^{2} \mathrm{~d} v^{2}
$$

and equation $(1,3)$, with $S=\xi-\xi_{0}$ where $\xi_{0}$ is a constant, will be

$$
\begin{aligned}
& \frac{1}{\xi-\eta} \frac{\partial}{\partial \xi}(\xi-\eta) \frac{\partial \varphi}{\partial \xi}+\frac{1}{\xi-\eta} \frac{\partial}{\partial \eta} \frac{1}{\xi-\eta} \frac{\partial \varphi}{\partial \eta}+\frac{f_{\xi}}{f} \frac{\partial \varphi}{\partial \xi}+ \\
& +\frac{1}{(\xi-\eta)^{2}} \frac{f_{\eta}}{f} \frac{\partial \varphi}{\partial \eta}+i k\left\{2 \frac{\partial \varphi}{\partial \xi}+\frac{\varphi}{\xi-\eta}+\frac{f_{\xi}}{f} \varphi\right\}=0
\end{aligned}
$$

where $f(\xi, \eta)=\sin \eta+(\xi-\eta) \cos \eta$

and

$$
\tilde{\varphi}=\varphi \exp \left\{i k\left(\xi-\xi_{0}\right)\right\}
$$


The boundary condition on the sphere will be

$$
\varphi=0, \text { if } \xi=\eta
$$

and at infinity the solution must be of the form

$$
\tilde{\varphi}=e^{i k x}+g(\theta) \frac{e^{i k r}}{r}
$$

where $g(\theta)$ is a finite amplitude function.

Before we give an asymptotic solution of equation $(2,4)$, we will extend the class of solutions of equation $(1,1)$. Instead of solutions of the form $(1,2)$, we assume that $\tilde{\varphi}$ can be written in the form

$$
\tilde{\varphi}(\mathbf{x}, k)=\varphi(\mathbf{x}, k) \exp \left\{i k S(\mathbf{x})-k^{s} \psi(\mathbf{x})\right\} .
$$

Inserting $(2,5)$ in $(1,1)$ yields

$$
\begin{aligned}
& k^{2}\left[1-(\nabla S)^{2}\right] \varphi 2 i k^{1+s} \varphi \nabla S \cdot \nabla \psi+i k[2 \nabla \varphi \cdot \nabla S+\varphi \Delta S]+ \\
& +k^{2 s} \varphi(\nabla \psi)^{2}-k^{s}[2 \nabla \varphi \cdot \nabla \psi+\varphi \Delta \psi]+\Delta \varphi=0 .
\end{aligned}
$$

We now have to determine the functions $\varphi, S$ and $\psi$ and the constant $s$ for large values of $k$. The term with the highest power of $k$ in equation $(2,6)$ depends on the values of the constant $s$. If $k$ is large, we find an asymptotic solution of the wave function by making this term equal to zero.

From $s>1$ follows that

$$
(\nabla \psi)^{2}=0
$$

and if $\psi$ has a real solution, we see that $\psi$ is a constant and form $(2,5)$ differs only a constant from form $(1,2)$, so no more information is obtained.

Therefore $s$ will be restricted to the range $0<s<1$. In this case the first term of $(2,6)$ contains the highest power of $k$. By making this term equal to zero, we get

$$
1-(\nabla S)^{2}=0
$$

This equation is the same, when $s=0(1,4)$. After suppressing this term from equation $(2,6)$, we notice that the second term contains the highest power of $k$. This leads to the equation

$$
\nabla S \cdot \nabla \psi=0
$$

which means that surfaces $\psi=$ constant are perpendicular to surfaces $S=$ constant. 
The next term with the highest power of $k$ will, in the case of $\frac{1}{2}<s<1$, give

$$
(\nabla \psi)^{2}=0
$$

and as before this is not applicable for our purpose. So we stay within the range $0<s \leqq \frac{1}{2}$. As we will see later, it is not necessary to consider $s=\frac{1}{2}$.

We now return to the newly introduced ray-coordinates $(\xi, \eta)$ and a solution of $(2,7)$ will be

$$
S=\xi-\xi_{0}
$$

where $\xi_{0}$ is a constant, and from $(2,8)$ follows that $\psi$ is a function of the variable $\eta$ only.

In the next sections we will try to find a solution of the form

$$
\tilde{\varphi}(\xi, \eta)=\varphi(\xi, \eta) \exp \left\{i k\left(\xi-\xi_{0}\right)-k^{s} \psi(\eta)\right\}
$$

with $0<s<\frac{1}{2}$ and

$$
\varphi(\xi, \eta)=k^{r_{0}} \sum_{n=0}^{\infty} k^{-n / p} \varphi_{n}(\xi, \eta)
$$

where $r_{0}$ and $p$ are yet to be determined.

If we write $\varphi(\xi, \eta)$ in this form, we see that $\varphi_{0}(\xi, \eta)$ must be a solution of

$$
2 \frac{\partial \varphi_{0}}{\partial \xi}+\frac{\varphi_{0}}{\xi-\eta}+\frac{f_{\xi}}{f} \varphi_{0}=0
$$

and we find recurrence relations between the other $\varphi_{n}$, if we take each power of $k$ equal to zero. These recurrence relations depend on $p$ and $s$, so we have to find these constants first. A solution of $(2,10)$ has the form

$$
\varphi_{0}=\frac{A(\eta)}{[(\xi-\eta) f(\xi, \eta)]^{\frac{1}{2}}}=\frac{A(\eta)}{[(\xi-\eta)\{\sin \eta+(\xi-\eta) \cos \eta\}]^{\frac{1}{2}}} .
$$

So we expect $\tilde{\varphi}$ to be asymptotically of the form

$$
\tilde{\varphi}_{a s}=\frac{A(\eta) k^{r_{0}} \exp \left\{i k\left(\xi-\xi_{0}\right)-k^{s} \psi(\eta)\right\}}{[(\xi-\eta)\{\sin \eta+(\xi-\eta) \cos \eta\}]^{\frac{1}{2}}}
$$

There are some constants and unknown functions in $(2,12)$ to be determined, viz. $r_{0}, s, A(\eta)$ and $\psi(\eta)$. 
This is not possible with the boundary condition which requires $\tilde{\varphi}=0$ on the sphere, where $\xi=\eta$. As we see $\tilde{\varphi}_{a s}$ is singular at this line. We also have a condition at infinity where the radiation condition has to be satisfied. This cannot be done, because near the shadow boundary $\left(\eta=\frac{1}{2} \pi\right)$ and large values of $\xi-\eta$

$$
\tilde{\varphi}_{a s} \approx \frac{M \exp \left\{i k\left(\xi-\xi_{0}\right)\right\}}{(\xi-\eta)^{\frac{1}{2}}}
$$

and off the shadow boundary

$$
\tilde{\varphi}_{a s} \approx \frac{N(\eta) \exp \left\{i k\left(\xi-\xi_{0}\right)\right\}}{\xi-\eta}
$$

Therefore $(2,12)$ cannot be a solution of our problem, but it leads us to the method which yields the right solution. We will give an asymptotic solution by means of boundary layer expansions in the neighbourhood of the sphere and the shadow boundary.

\section{BOUNDARY LAYER EXPANSION NEAR THE SPHERE AND THE SHADOW BOUNDARY}

We will try to find a solution in the region $\xi-\eta \approx 0$ and $\eta \approx \frac{1}{2} \pi$. To find a solution of the Helmholtz equation for large values of $k$ in this region, we introduce new variables $\alpha$ and $\beta$ as follows

$$
\begin{aligned}
& \alpha=k^{\lambda}\left(\xi-\frac{\pi}{2}\right), \\
& \beta=k^{\lambda}\left(\eta-\frac{\pi}{2}\right),
\end{aligned}
$$

where $\lambda$ is a positive constant and

$$
\begin{aligned}
& \beta<\alpha<\infty, \\
& 0<\beta<\infty
\end{aligned}
$$

We first consider the shadow region where $\beta$ is positive and $\tilde{\varphi}=\tilde{\varphi}_{d}(1,7)$ and we expect the solution to be of the form

$$
\tilde{\varphi}_{d}=\varphi_{1} \exp \left\{i k\left(\xi-\xi_{o}\right)\right\}
$$


If we put this in the differential equation with the new coordinates $(\alpha, \beta)$, we get the equation

$$
\begin{aligned}
& \frac{k^{2 \lambda}}{\alpha-\beta} \frac{\partial}{\partial \alpha}(\alpha-\beta) \frac{\partial \varphi_{1}}{\partial \alpha}+\frac{k^{4 \lambda}}{\alpha-\beta} \frac{\partial}{\partial \beta} \frac{1}{\alpha-\beta} \frac{\partial \varphi_{1}}{\partial \beta}+k^{\lambda} \frac{f_{\xi}}{f} \frac{\partial \varphi_{1}}{\partial \alpha}+ \\
& +\frac{k^{3 \lambda}}{\alpha-\beta} \frac{f_{\eta}}{f} \frac{\partial \varphi_{1}}{\partial \beta}+i k\left\{2 k^{\lambda} \frac{\partial \varphi_{1}}{\partial \alpha}+k^{\lambda} \frac{\varphi_{1}}{\alpha-\beta}+\frac{f_{\xi}}{f} \varphi_{1}\right\}=0
\end{aligned}
$$

where $f(\xi, \eta)=\sin \eta+(\xi-\eta) \cos \eta$.

We want to find a solution of equation $(3,3)$ for large values of $k$ and expect to get this asymptotic solution of $\varphi_{1}$ by equating the term with the highest power of $k$ to zero. As we see we have to distinguish several cases dependent on the value of $\lambda$.

1. If $\lambda<\frac{1}{3}$, the main contribution to the asymptotic expansion will be given by the equation

$$
2 \frac{\partial \varphi_{1 a s}}{\partial \alpha}+\frac{\varphi_{1 a s}}{\alpha-\beta}=0
$$

This equation has a solution which is singular, if $\alpha-\beta$ tends to zero, however, we need a regular solution and obviously this cannot be found in this case.

2. We now consider the case $\lambda=\frac{1}{3}$. If we put this in equation $(3,3)$ and equate the term with the highest power of $k$ to zero, the asymptotic solution $\varphi_{10}$ will be found by solving the equation

$$
\frac{1}{\alpha-\beta} \frac{\partial}{\partial \beta} \frac{1}{\alpha-\beta} \frac{\partial \varphi_{10}}{\partial \beta}+2 i \frac{\partial \varphi_{10}}{\partial \alpha}+i \frac{\varphi_{10}}{\alpha-\beta}=0
$$

with the boundary condition

$$
\varphi_{10}=0, \quad \text { if } \alpha=\beta
$$

and the radiation condition at infinity.

Strictly speaking the asymptotic solution of $(3,3)$ has the following form

$$
\varphi_{1}=k^{r_{1}} \sum_{n=0}^{\infty} k^{-n / 3} \varphi_{1 n} .
$$


If we substitute this expansion into $(3,3)$ and equate the coefficients of each power of $k$ to zero, we obtain a set of recurrence relations of $\varphi_{1 n}$ and $\varphi_{10}$ must be a solution of $(3,4)$. However, the general equation for $\varphi_{1 n}$ is rather complicated and difficult to solve, so we consider only the first term of $(3,5)$ and assume that this will give an asymptotic expansion of $\varphi_{1}$ for large values of $k$. To solve $(3,4)$ we introduce a new function $\chi$ and new variables $p$ and $q$ as follows

$$
\begin{aligned}
\varphi_{10} & =\chi \exp \left\{\frac{-i(\alpha-\beta)^{3}}{3}\right\} \\
p & =2^{-\frac{2}{3}}(\alpha-\beta)^{2}=\left(\frac{k}{2}\right)^{\frac{2}{3}}(\xi-\eta)^{2} \\
q & =2^{-\frac{1}{3}} \alpha=\left(\frac{k}{2}\right)^{\frac{1}{3}}\left(\xi-\frac{\pi}{2}\right)
\end{aligned}
$$

If we put this in equation $(3,4)$, we find that $\chi$ must be a solution of the following parabolic differential equation

$$
\frac{\partial^{2} \chi}{\partial p^{2}}+i \frac{\partial \chi}{\partial q}+p \chi=0
$$

with boundary condition

$$
\chi=0, \text { if } p=0 .
$$

However, this function is valid in the region near the sphere and the shadow-boundary, hence the radiation condition need not be satisfied by $\chi$. We therefore only require that $\chi$ be zero on the sphere, where $p=0$.

We suppose the solution of $(3,7)$ is of the form

$$
\chi=\int_{C} F(p, t) e^{i t q} \mathrm{~d} t
$$

where $C$ is a contour which will be discussed later on.

If we put $(3,9)$ in equation $(3,7)$, we get the following differential equation for $F(p, t)$

$$
F_{p p}-(t-p) F=0
$$

with the boundary condition

$$
F(p, t)=0, \text { if } p=0 .
$$


A solution of $(3,10)$ which fulfils the boundary condition can be given as a combination of Airy functions

$$
F(p, t)=A\left\{w_{2}(t-p)-\frac{w_{2}(t)}{w_{1}(t)} w_{1}(t-p)\right\},
$$

where $\quad w_{1}(t)=e^{\frac{2 \pi i}{3}} / \frac{\pi}{3}(-t)^{\frac{1}{2}} H_{\frac{1}{3}}^{(1)}\left\{\frac{2}{3}(-t)^{\frac{3}{2}}\right\}$.

$H_{\frac{1}{3}}^{(1)}$ is a Hankel function of the first kind and order $\frac{1}{3}$ and $w_{2}(t)$ is the complex conjugate function of $w_{1}(t)$. We have

$$
\begin{aligned}
& w_{1}(t)=u(t)+i v(t), \\
& w_{2}(t)=u(t)-i v(t) .
\end{aligned}
$$

If we put these functions in $(3,9)$, we get the solution

$$
\chi=A \int_{C} e^{i t q}\left\{w_{2}(t-p)-\frac{w_{2}(t)}{w_{1}(t)} w_{1}(t-p)\right\} \mathrm{d} t .
$$

The contour $C$ will be taken around all singularities of the integrand. The only singularities are the zeros of the function $w_{1}(t)$, which are points on the line $t=\varrho e^{\frac{1}{3} \pi i}$ for real positive $\varrho$. We define $C$ as the contour which runs from $\infty e^{\frac{2}{3} \pi i}$ over 0 to $\infty$. This contour can be closed at infinity in the half plane, where the imaginary part of $t$ is positive. The integral along this closing line is equal to zero.

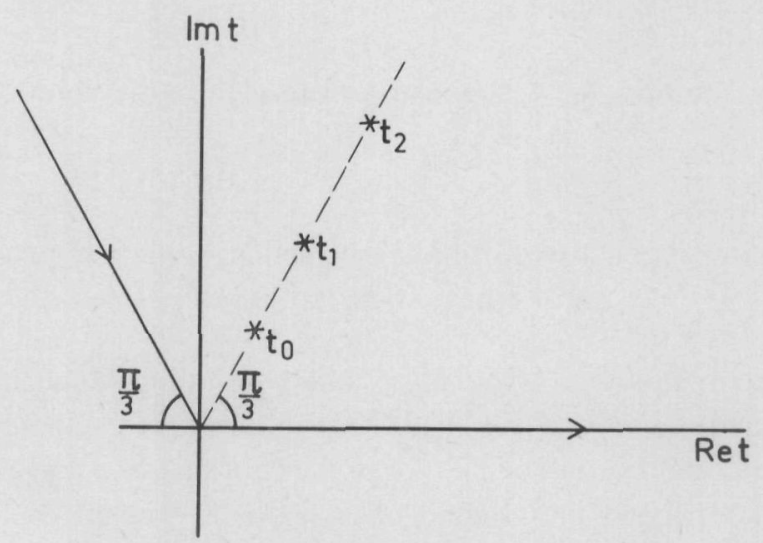

Fig. 2 
The constant $A$ follows from the condition at infinity (or finite distance to the sphere).

In the nearby region we have found an asymptotic solution of $(2,4)$

$$
\varphi_{1} \approx k^{r_{1}} A \exp \left(-i \frac{2}{3} p^{\frac{3}{2}}\right) \int_{C} e^{i t q}\left\{w_{2}(t-p)-\frac{w_{2}(t)}{w_{1}(t)} w_{1}(t-p)\right\} \mathrm{d} t
$$

with $\quad p=\left(\frac{k}{2}\right)^{\frac{2}{3}}(\xi-\eta)^{2}$,

$$
q=\left(\frac{k}{2}\right)^{\frac{1}{3}}\left(\xi-\frac{\pi}{2}\right)
$$

and on the shadow boundary with $\eta=\frac{1}{2} \pi$ we have $p=q^{2}$.

At finite distance we require that on the shadow boundary

$$
\tilde{\varphi}_{d}=\tilde{\varphi}_{\mathrm{inc}},
$$

because this solution $\tilde{\varphi}_{d}$ is a continuation of the asymptotic solution in the lit region.

If we take $r_{1}=0$ and $A=i / 4 \pi^{\frac{1}{2}}$, then $(3,12)$ is the solution which meets condition $(3,13)$ (Appendix).

If we expand $(3,12)$ for large values of $p$ and $q$, we use the method of steepest descent and we will see that the first part of the integral yields the incoming wave and the second part the reflected wave, which is zero on the shadow boundary [16].

In this way we have found near the object and the shadow boundary the asymptotic solution of the Helmholtz equation of the form

$$
\tilde{\varphi}_{d} \approx \frac{i}{4 \pi^{\frac{1}{2}}} \exp \left\{i k\left(\xi-\frac{\pi}{2}\right)-i \frac{2}{3} p^{\frac{3}{2}}\right\} \int_{C} e^{i t q}\left\{w_{2}(t-p)-\frac{w_{2}(t)}{w_{1}(t)} w_{1}(t-p)\right\} \mathrm{d} t .
$$

By means of this solution we will construct an asymptotic solution in the whole shadow region.

\section{ASYMPTOTIC EXPANSION NEAR THE SPHERE AT FINITE DISTANCE FROM THE SHADOW BOUNDARY}

It is obvious that in this region we must find a solution which is an asymptotic solution of $(1,1)$ and a continuation of $(3,14)$. We therefore evaluate $(3,14)$ for finite values of $\eta-\frac{1}{2} \pi$ and small values of $\xi-\eta$ or in the coordinates $p$ and $q: p-q^{2}=0(1)$.

In this region we expand the integral of $(3,14)$ as a sum of residues because the zeros $t_{s}$ of $w_{1}(t)$ are the only singularities of the integrand. 
We have

$$
t_{s}=\varrho_{s} e^{\frac{\pi i}{3}}
$$

with $s=0,1, \ldots$

These zeros are simple zeros, so we get the following result

$$
\tilde{\varphi}_{d} \approx \frac{\pi^{\frac{1}{2}}}{2} \exp \left\{i k\left(\xi-\frac{\pi}{2}\right)-i \frac{2}{3} p^{\frac{3}{2}}\right\} \sum_{s=0}^{\infty} e^{i t_{s} q} \frac{w_{2}\left(t_{s}\right) w_{1}\left(t_{s}-p\right)}{w_{1}^{\prime}\left(t_{s}\right)}
$$

and with the relation

$$
w_{1}^{\prime}(t) w_{2}(t)-w_{1}(t) w_{2}^{\prime}(t)=-2 i
$$

which is the Wronski determinant of $w_{1}(t)$ and $w_{2}(t)$, we arrive at the following expansion

$$
\tilde{\varphi}_{d} \approx-i \pi^{\frac{1}{2}} \exp \left\{i k\left(\xi-\frac{\pi}{2}\right)-i \frac{2}{3} p^{\frac{3}{2}}\right\} \sum_{s=0}^{\infty} e^{i t_{s} q} \frac{w_{1}\left(t_{s}-p\right)}{\left\{w_{1}^{\prime}\left(t_{s}\right)\right\}^{2}}
$$

bearing in mind that $w_{1}\left(t_{s}\right)=0$.

If we expand this solution at finite distance to the sphere, which corresponds to large values of $p$, we get with the help of the asymptotic expansion of the Airy function

$$
w_{1}\left(t_{s}-p\right) \approx \frac{1}{p^{\frac{1}{4}}} \exp \left\{i\left(\frac{2}{3} p^{\frac{3}{2}}-t_{s} p^{\frac{1}{2}}+\frac{t_{s}^{2}}{4 p^{\frac{1}{2}}}+\frac{\pi}{4}\right)\right\}
$$

the following result

$$
\tilde{\varphi}_{d} \approx \frac{\left(\frac{k}{2}\right)^{-\frac{1}{6}} \pi^{\frac{1}{2}}}{\sqrt{(\xi-\eta)}} \exp \left\{i k\left(\xi-\frac{\pi}{2}\right)-\frac{\pi i}{4}\right\} \sum_{s=0}^{\infty} \frac{\exp \left\{i\left(\frac{k}{2}\right)^{\frac{1}{3}} t_{s}\left(\eta-\frac{\pi}{2}\right)\right\}}{\left\{w_{1}^{\prime}\left(t_{s}\right)\right\}^{2}}
$$

This solution is only valid at finite distance to the sphere and $\eta-\frac{1}{2} \pi$ large enough for the series to be rapidly convergent.

At large distance to the sphere we notice that this solution is not the right asymptotic expansion, because it does not satisfy the radiation condition. This will be worked out later on. We expect $(4,3)$ to be an asymptotic solution near the sphere at finite distance from the shadow boundary, as well.

To show this we suppose that at finite distance from the shadow boundary near the object the function $\tilde{\varphi}_{d}$ is a continuation of $(4,3)$ and for briefness' sake we consider one term $U_{s}$ of the series 


$$
\tilde{\varphi}_{d}=\sum_{s=0}^{\infty} \exp \left\{i\left(\frac{k}{2}\right)^{\frac{1}{3}} t_{s} \eta+i k \xi\right\} U_{s}(\xi, \eta ; k)
$$

and suppose that each term of the series should be a solution of the Helmholtz equation.

We follow the same procedure as before and it is clear that we have to stretch the coordinates by

and

$$
\xi-\eta=k^{-\frac{1}{3}} \gamma
$$

$$
U_{s}=k^{r_{2}} \sum_{n=0}^{\infty} k^{-\frac{n}{3}} U_{n s}(\gamma, \eta)
$$

The first term of the series will yield us the asymptotic expansion

$$
U_{s} \approx k^{r_{2}} U_{0 s}(\gamma, \eta)
$$

and after substitution in the Helmholtz equation and equating the coefficient of the highest power of $k$ to zero, we find the equation for $U_{0 s}$ and the boundary condition on the sphere

$$
\frac{1}{\gamma^{2}} \frac{\partial^{2} U_{0 s}}{\partial \gamma^{2}}+\frac{\partial U_{0 s}}{\partial \gamma}\left\{-\frac{1}{\gamma^{3}}-\frac{2 i t_{s}}{\gamma^{2}}+2 i\right\}+U_{0 s}\left\{\frac{i t_{s}}{\gamma^{3}}-\frac{t_{s}^{2}}{\gamma^{2}}+\frac{i}{\gamma}\right\}=0
$$

with $U_{0 s}=0$, if $\gamma=0$.

Introducing the variable $p=2^{-\frac{3}{3}} \gamma^{2}$, used previously, we find

$$
U_{0 s}=\exp \left\{i\left(t_{s} \gamma-\frac{1}{3} \gamma^{3}\right)\right\} w_{1}\left(t_{s}-p\right) G(\eta, s)
$$

where the function $G(\eta, s)$ is the integration constant which should be determined by the requirement that this solution is a continuation of the solution in the corner of the sphere and the shadow boundary, so, if we put $(4,6)$ in $(4,4)$, we have to match this one with $(4,1)$.

This matching is easily carried out when we transform the asymptotic solution

$$
\tilde{\varphi}_{d} \approx k^{r_{2}} \sum_{s=0}^{\infty} \exp \left\{i t_{s}\left(\frac{k}{2}\right)^{\frac{1}{3}} \eta+i k \xi+i\left(t_{s} \gamma-\frac{1}{3} \gamma^{3}\right)\right\} w_{1}\left(t_{s}-p\right) G(\eta, s)
$$

on the same coordinates used in form $(4,1)$.

We find

$$
\tilde{\varphi}_{d} \approx-i \pi^{\frac{1}{2}} \exp \left\{i k\left(\xi-\frac{\pi}{2}\right)-i \frac{2}{3} p^{\frac{3}{2}}\right\} g(\eta) k^{r_{2}} \sum_{s=0}^{\infty} e^{i t_{s} q} \frac{w_{1}\left(t_{s}-p\right)}{\left\{w_{1}^{\prime}\left(t_{s}\right)\right\}^{2}} .
$$


The function $g(\eta)$ and the exponent $r_{2}$ must still be determined. From the matching condition follows that

$$
\lim _{\eta \rightarrow \frac{\pi}{2}} g(\eta)=1, \quad r_{2}=0
$$

In the following section we will see that this function $g(\eta)$ can be determined by matching $(4,7)$ and the solution at finite distance to the sphere.

\section{ASYMPTOTIC EXPANSION AT FINITE DISTANCE TO THE SPHERE}

In section 2 we discussed the asymptotic expansion of the field in the region where the distance to the sphere was finite $(2,12)$. We compare this solution with $(4,3)$ and the expansion for large values of $p$ of $(4,7)$ and match these solutions by pointing out that in the region where $\xi-\eta$ is small but finite $(2,12)$ and $(4,3)$ are valid. Hence at finite distance to the sphere we assume the solution to be

$$
\tilde{\varphi}_{d} \approx \frac{\left(\frac{k}{2}\right)^{-\frac{1}{6}} \pi^{\frac{1}{2}} \exp \left\{i k\left(\xi-\frac{\pi}{2}\right)-\frac{\pi i}{4}\right\}}{[(\xi-\eta)\{\sin \eta+(\xi-\eta) \cos \eta\}]^{\frac{1}{2}}} \sin ^{\frac{1}{2} \eta} \sum_{s=0}^{\infty} \frac{\exp \left\{i\left(\frac{k}{2}\right)^{\frac{1}{3}} t_{s}\left(\eta-\frac{\pi}{2}\right)\right\}}{\left\{w_{1}^{\prime}\left(t_{s}\right)\right\}^{2}} .
$$

This solution is a continuation of $(4,3)$, valid in the region $\eta \approx \frac{1}{2} \pi$, which we continuate in the region where $\eta-\frac{1}{2} \pi=O(1)$ and it corresponds to the form required by $(2,12)$. Matching $(5,1)$ and $(4,7)$, we find

$$
g(\eta)=1
$$

Remembering that $t_{s}$, the zeros of $w_{1}(t)$, are points on the line $t=\varrho e^{\frac{1}{3} \pi i}$ in the complex $t$-plane, we notice that the series of $(5,1)$ is convergent, if $\eta-\frac{1}{2} \pi>0$.

In the region $\eta \approx \frac{1}{2} \pi$ the series converges slowly and therefore we take, instead of this series representation, the solution in integral form analogous to $(3,14)$. This is done in section 7 , where we give the final solution.

\section{ASYMPTOTIC EXPANSION NEAR THE AXIS OF SYMMETRY}

Solution $(5,1)$ is infinite on the axis of symmetry which is the line

$$
\sin \eta+(\xi-\eta) \cos \eta=0
$$

and obviously the assumption of section 1 , that the gradients are moderate is violated, so we have to look for an other solution in the neighbourhood of that line. In the gen- 
eral three-dimensional case we will not find a line of singularities, but a surface, which we call the caustic surface. In our problem this surface is degenerated to the axis of symmetry.

In the neigbourhood of this axis of symmetry we have

$$
\sin \eta+(\xi-\eta) \cos \eta \approx 0
$$

and we try to find an asymptotic solution by introducing the new variable $\delta$ and $\zeta$ as follows

$$
\begin{aligned}
\sin \eta+(\xi-\eta) \cos \eta & =k^{-\mu} \delta \\
\xi-\eta & =\zeta
\end{aligned}
$$

where $\mu$ is a positive constant which will be determined by the stretching condition.

From the form of the solution in the outside region we expect the solution of the form

$$
\tilde{\varphi}_{d}=\sum_{s=0}^{\infty} \exp \left\{i k \xi+i\left(\frac{k}{2}\right)^{\frac{1}{3}} t_{s} \eta\right\} U_{s}(\xi, \eta ; k)
$$

where $U_{s}$ is asymptotically

$$
U_{s}(\xi, \eta ; k)=k^{r_{3}} \sum_{n=0}^{\infty} U_{n s}(\xi, \eta) k^{-n \mu} .
$$

In the new variables we get the equation for $U_{s}(\xi, \eta ; k)$ as a function of $\zeta$ and $\delta$

$$
\begin{aligned}
& \frac{1}{\zeta}\left(k^{\mu} \cos \eta \frac{\partial}{\partial \delta}+\frac{\partial}{\partial \zeta}\right)\left\{\zeta\left(k^{\mu} \cos \eta \frac{\partial U_{s}}{\partial \delta}+\frac{\partial U_{s}}{\partial \zeta}\right)\right\}+ \\
& +\frac{1}{\zeta}\left\{-i\left(\frac{k}{2}\right)^{\frac{1}{3}} t_{s}+k^{\mu} \zeta \sin \eta \frac{\partial}{\partial \delta}+\frac{\partial}{\partial \zeta}\right\} \times \\
& \times\left[\frac{1}{\zeta}\left\{-i\left(\frac{k}{2}\right)^{\frac{1}{3}} t_{s} U_{s}+k^{\mu} \zeta \sin \eta \frac{\partial U_{s}}{\partial \delta}+\frac{\partial U_{s}}{\partial \zeta}\right\}\right]+ \\
& +\frac{k^{\mu} \cos \eta}{\delta}\left(k^{\mu} \cos \eta \frac{\partial U_{s}}{\partial \delta}+\frac{\partial U_{s}}{\partial \zeta}\right)+\frac{k^{\mu} \sin \eta}{\zeta \delta} \times \\
& \times\left\{-i\left(\frac{k}{2}\right)^{\frac{1}{3}} t_{s} U_{s}+k^{\mu} \zeta \sin \eta \frac{\partial U_{s}}{\partial \delta}+\frac{\partial U_{s}}{\partial \zeta}\right\}+ \\
& +i k\left\{2\left(k^{\mu} \cos \eta \frac{\partial U_{s}}{\partial \delta}+\frac{\partial U_{s}}{\partial \zeta}\right)+\frac{U_{s}}{\zeta}+\frac{k^{\mu} \cos \eta}{\delta} U_{s}\right\}=0 .
\end{aligned}
$$


The stretching condition implies that $1+\mu=2 \mu$, from which follows that $\mu=1$.

If we put $(6,3)$ in equation $(6,4)$ and equate the term with the highest power of $k$ to zero, we get the first term of the approximation as a solution of the following equation

$$
\frac{\partial^{2} U_{0 s}}{\partial \delta^{2}}+\frac{1}{\delta} \frac{\partial U_{0 s}}{\partial \delta}+2 i \cos \eta \frac{\partial U_{0 s}}{\partial \delta}+\frac{i \cos \eta}{\delta} U_{0 s}=0
$$

with $\quad \cos \eta=\frac{1}{\left(1+\zeta^{2}\right)^{\frac{1}{2}}}$ independent of $\delta$.

The solution of $(6,5)$ can be obtained by means of the substitution

$$
U_{0 s}=\exp (-i \delta \cos \eta) F
$$

where $F$ is a solution of the Bessel equation

$$
F_{\delta \delta}+\frac{1}{\delta} F_{\delta}+\cos ^{2} \eta F=0
$$

In the region $\delta>0$ we take the solution which meets the radiation condition

$$
U_{0 s}=H_{s}(\zeta) \exp (-i \delta \cos \eta) H_{0}^{(1)}(\delta \cos \eta)
$$

and if we put it in equation $(6,2)$, we get the asymptotic solution for $\tilde{\varphi}_{d}$

$$
\tilde{\varphi}_{d} \approx k^{r_{3}} \sum_{s=0}^{\infty} \exp \left\{i k \xi+i\left(\frac{k}{2}\right)^{\frac{1}{3}} t_{s} \eta-i \delta \cos \eta\right\} H_{s}(\zeta) H_{0}^{(1)}(\delta \cos \eta) .
$$

The unknown constant $r_{3}$ and the function $H_{s}(\zeta)$ will be determined by matching this solution and the expansion near the sphere or the far field.

For large values of $\delta$ we obtain from the asymptotic expression for $H_{0}^{(1)}(\delta \cos \eta)$ the solution in $\xi, \eta$ coordinates

$$
\begin{aligned}
& \tilde{\varphi}_{d} \approx k^{r_{3}}\left[\frac{2}{\pi k\{\sin \eta+(\xi-\eta) \cos \eta\} \cos \eta}\right]^{\frac{1}{2}} \times \\
& \times \sum_{s=0}^{\infty} \exp \left\{i k \xi+i\left(\frac{k}{2}\right)^{\frac{1}{3}} t_{s} \eta-\frac{\pi i}{4}\right\} H_{s}(\xi-\eta)
\end{aligned}
$$

which should be equal to $(5,1)$. 
Comparing these two solutions we find $r_{3}=\frac{1}{3}$.

$$
H_{s}(\xi-\eta)=\frac{2^{-\frac{1}{3}} \pi}{\sqrt{\xi}-\eta} \frac{\exp \left\{-i k \frac{\pi}{2}-i\left(\frac{k}{2}\right)^{\frac{1}{3}} t_{s} \frac{\pi}{2}\right\}}{\left\{w_{1}^{\prime}\left(t_{s}\right)\right\}^{2}}(\sin \eta \cos \eta)^{\frac{1}{2}}
$$

Hence we arrived at the solution near the axis of symmetry of the form

$$
\begin{aligned}
\tilde{\varphi}_{d} & \approx\left(\frac{k}{2}\right)^{\frac{1}{3}} \frac{\pi}{\sqrt{\zeta}-\eta} \exp \left\{\mathrm{ik}\left(\xi-\frac{\pi}{2}\right)-i k[\sin \eta+(\xi-\eta) \cos \eta] \cos \eta\right\}(\sin \eta \cos \eta)^{\frac{1}{2}} \times \\
& \times H_{0}^{(1)}\{k[\sin \eta+(\xi-\eta) \cos \eta] \cos \eta\} \sum_{s=0}^{\infty} \frac{\exp \left\{i\left(\frac{k}{2}\right)^{\frac{1}{3}} t_{s}\left(\eta-\frac{\pi}{2}\right)\right\}}{\left\{w_{1}^{\prime}\left(t_{s}\right)\right\}^{2}}
\end{aligned}
$$

This solution is still incomplete. Moreover it is singular on the line $\sin \eta+(\xi-\eta)$ $\cos \eta=0$.

We obtain the total solution by adding the contribution of the ray generated by the tangent ray on the other side of the sphere. As we will see a combination of the form

$$
\exp (-i \delta \cos \eta) H_{0}^{(1)}(\delta \cos \eta)+\exp (i \delta \cos \eta) H_{0}^{(2)}(\delta \cos \eta)
$$

will be obtained instead of

$$
\exp (-i \delta \cos \eta) H_{0}^{(1)}(\delta \cos \eta)
$$

which yields a finite result, if $\delta$ tends to zero.

Solution $(6,9)$ is singular on the sphere $\xi=\eta$ also. Hence we determine a solution on the axis of symmetry near the sphere. This solution must be a continuation of the one near the sphere and it is obvious that an asymptotic expansion in this region will be obtained by stretching $\xi-\eta$ also.

However, we will compare the two solutions and in this way arrive at the solution near the sphere and the axis of symmetry.

If we use the $p, q$ coordinates defined in section 3 and compare $(6,9)$ with $(5,1)$ and $(4,1)$ we get

$$
\begin{aligned}
& \tilde{\varphi}_{d} \approx \pi \exp \left\{i k\left(\xi-\frac{\pi}{2}\right)-i k[\sin \eta+(\xi-\eta) \cos \eta] \cos \eta-i \frac{2}{3} p^{\frac{3}{2}}-\frac{\pi i}{4}\right\} \times \\
& \times H_{0}^{(1)}\{k[\sin \eta+(\xi-\eta) \cos \eta] \cos \eta\}(\sin \eta \cos \eta)^{\frac{1}{2}} \sum_{s=0}^{\infty} e^{i t_{s} q} \frac{w_{1}\left(t_{s}-p\right)}{\left\{w_{1}^{\prime}\left(t_{s}\right)\right\}^{2}}
\end{aligned}
$$


As we already mentioned the final solution in the shadow region will be obtained by putting the contributions of all possible rays together. However, it is clear that the parts which are the results from the first round of the creeping rays, are the main contribution to the field. If possible we add up all rays, otherwise we deal with the main part. We consider five regions (Fig. 3.).

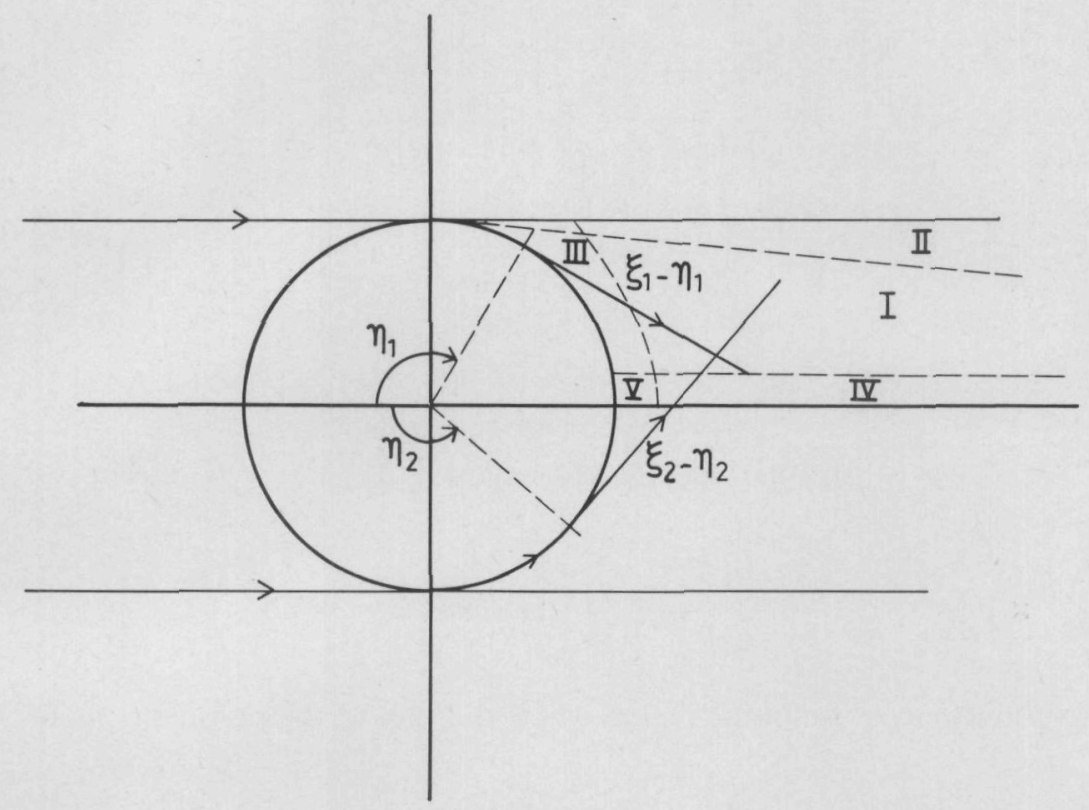

Fig. 3

\section{The region where}

$$
\begin{aligned}
& \eta_{1} \gg \frac{\pi}{2}, \quad \xi_{1} \gg \eta_{1}, \\
& \eta_{2} \gg \frac{\pi}{2}, \quad \xi_{2} \gg \eta_{2}
\end{aligned}
$$

and $\quad \sin \eta_{1,2}+\left(\xi_{1,2}-\eta_{1,2}\right) \cos \eta_{1,2}=O(1)$.

This latter condition states that the distance from the axis is finite. In section 5 we dealt with this matter. The final solution will be built up by solutions of the form $(5,1)$, where we take 


$$
\begin{aligned}
& \xi=\xi_{1}+2 \pi m, \\
& \eta=\eta_{1}+2 \pi m
\end{aligned}
$$

and

$$
\begin{aligned}
& \xi=\xi_{2}+2 \pi m, \\
& \eta=\eta_{2}+2 \pi m, \quad(m=0,1,2, \ldots)
\end{aligned}
$$

respectively, and sum over $m$ which is quite simple,

$$
\begin{aligned}
& \tilde{\varphi}_{d, \text { tot }}=\frac{\left(\frac{k}{2}\right)^{-\frac{1}{6}} \pi^{\frac{1}{2}} \exp \left\{i k\left(\xi_{1}-\frac{\pi}{2}\right)-\frac{\pi i}{4}\right\} \sin ^{\frac{1}{2}} \eta_{1}}{\left\{\left(\xi_{1}-\eta_{1}\right)\left[\sin \eta_{1}+\left(\xi_{1}-\eta_{1}\right) \cos \eta_{1}\right]\right\}^{\frac{1}{2}}} \times \\
& \times \sum_{s=0}^{\infty} \frac{\exp \left\{i\left(\frac{k}{2}\right)^{\frac{1}{3}} t_{s}\left(\eta_{1}-\frac{\pi}{2}\right)\right\}}{\left\{w_{1}^{\prime}\left(t_{s}\right)\right\}^{2}}\left[1-\exp \left\{2 i k \pi+2 i\left(\frac{k}{2}\right)^{\frac{1}{3}} t_{s} \pi\right\}\right]^{-1}+ \\
&+\frac{\left(\frac{k}{2}\right)^{-\frac{1}{6}} \pi^{\frac{1}{2}} \exp \left\{i k\left(\xi_{2}-\frac{\pi}{2}\right)-\frac{\pi i}{4}\right\} \sin ^{\frac{1}{2}} \eta_{2}}{\left\{\left(\xi_{2}-\eta_{2}\right)\left[\sin \eta_{2}+\left(\xi_{2}-\eta_{2}\right) \cos \eta_{2}\right]\right\}^{\frac{1}{2}}} \times \\
& \times \sum_{s=0}^{\infty} \frac{\exp \left\{i\left(\frac{k}{2}\right)^{\frac{1}{3}} t_{s}\left(\eta_{2}-\frac{\pi}{2}\right)\right\}}{\left\{w_{1}^{\prime}\left(t_{s}\right)\right\}^{2}}\left[1-\exp \left\{2 i k \pi+2 i\left(\frac{k}{2}\right)^{\frac{1}{3}} t_{s} \pi\right\}\right]^{-1} .
\end{aligned}
$$

This solution we can use in the region where the sum of the residues is finite.

\section{The region where}

$$
\begin{aligned}
& \eta_{1} \approx \frac{\pi}{2}, \quad \xi_{1} \gg \eta_{1}, \\
& \eta_{2} \gg \frac{\pi}{2}, \quad \xi_{2} \gg \eta_{2} .
\end{aligned}
$$

The distance to the axis is finite. The solution again consists of two parts as in $(7,1)$ and again we take

and

$$
\begin{aligned}
& \xi=\xi_{1}+2 \pi m, \\
& \eta=\eta_{1}+2 \pi m
\end{aligned}
$$

$$
\begin{aligned}
& \xi=\xi_{2}+2 \pi m, \\
& \eta=\eta_{2}+2 \pi m, \quad(m=0,1,2, \ldots)
\end{aligned}
$$


respectively. However, only $m=0$ will give here an important contribution, because, as we explained before, the first part $\left(\eta=\eta_{1}\right)$ of the solution tends to $\tilde{\varphi}_{\text {inc }}$ and the other parts are exponentially small because of the behaviour of $t_{s}$. But for completeness' sake we will give the total solution. The contribution of $\eta=\eta_{1}$, will be given in the integral representation and the remainder as a sum of residues and sum over $m$. So we get

$$
\begin{aligned}
\tilde{\varphi}_{d, \text { tot }}= & \frac{i}{4 \pi^{\frac{1}{2}}} \frac{\exp \left\{i k\left(\xi_{1}-\frac{\pi}{2}\right)-i \frac{2}{3} p_{1}{ }^{\frac{3}{2}}\right\} \sin ^{\frac{1}{2}} \eta_{1}}{\left\{\sin \eta_{1}-\left(\xi_{1}-\eta_{1}\right) \cos \eta_{1}\right\}^{\frac{1}{2}}} \times \\
& \times \int_{C} e^{i t q_{1}}\left\{w_{2}\left(t-p_{1}\right)-\frac{w_{2}(t)}{w_{1}(t)} w_{1}\left(t-p_{1}\right)\right\} \mathrm{d} t+ \\
+ & \frac{\left(\frac{k}{2}\right)^{-\frac{1}{6}} \pi^{\frac{1}{2}} \exp \left\{i k\left(\xi_{1}+\frac{3 \pi}{2}\right)-\frac{\pi i}{4}\right\} \sin ^{\frac{1}{2}} \eta_{1}}{\left\{\left(\xi_{1}-\eta_{1}\right)\left[\sin \eta_{1}+\left(\xi_{1}-\eta_{1}\right) \cos \eta_{1}\right]\right\}^{\frac{1}{2}}} \times \\
& \times \sum_{s=0}^{\infty} \frac{\exp \left\{i\left(\frac{k}{2}\right)^{\frac{1}{3}} t_{s}\left(\eta_{1}+\frac{3 \pi}{2}\right)\right\}}{\left\{w_{1}^{\prime}\left(t_{s}\right)\right\}^{2}}\left[1-\exp \left\{2 i k \pi+2 i\left(\frac{k}{2}\right)^{\frac{1}{3}} t_{s} \pi\right\}\right]^{-1}+ \\
+ & \frac{\left(\frac{k}{2}\right)^{-\frac{1}{6}} \pi^{\frac{1}{2}} \exp \left\{i k\left(\xi_{2}-\frac{\pi}{2}\right)-\frac{\pi i}{4}\right\} \sin ^{\frac{1}{2}} \eta_{2}}{\left\{\left(\xi_{2}-\eta_{2}\right)\left[\sin \eta_{2}+\left(\xi_{2}-\eta_{2}\right) \cos \eta_{2}\right]\right\}^{\frac{1}{2}} \times} \\
& q_{1}=\left(\frac{k}{2}\right)^{\frac{1}{3}}\left(\xi_{1}-\frac{\pi}{2}\right) \cdot \\
& \times \sum_{s=0}^{\infty} \frac{\exp \left\{i\left(\frac{k}{2}\right)^{\frac{1}{3}} t_{s}\left(\eta_{2}-\frac{\pi}{2}\right)\right\}}{\left\{w_{1}^{\prime}\left(t_{s}\right)\right\}^{2}}\left[1-\exp \left\{2 i k \pi+2 i\left(\frac{k}{2}\right)^{\frac{1}{3}} t_{s} \pi\right\}\right]^{-1} \\
p_{1} & =\left(\frac{k}{2}\right)^{\frac{2}{3}}\left(\xi_{1}-\eta_{1}\right)^{2},
\end{aligned}
$$

This solution is valid for large values of $\xi_{1}-\eta_{1}$, hence $p_{1}$ and $q_{1}$ are very large and we may expand the integral part of the solution by means of the method of steepest descent. (Appendix). 


\section{The region where}

and

$$
\begin{aligned}
& \xi_{1} \approx \eta_{1}, \\
& \xi_{2} \approx \eta_{2}
\end{aligned}
$$

$$
\sin \eta_{1,2}+\left(\xi_{1,2}-\eta_{1,2}\right) \cos \eta_{1,2}=O(1)
$$

This is the region near the sphere in the neighbourhoud of the shadow boundary and at finite distance to this region. However, this region is bounded in the direction of the axis, because $\sin \eta+(\xi-\eta) \cos \eta$ must be finite.

Near the sphere we use solution $(4,7)$ with the function $g(\eta)$ given in $(5,2)$. But this solution is only used in the region where the series are rapidly convergent, i.e. at finite distance from the shadow boundary. We use the same variable as in section 4 .

$$
\begin{aligned}
& p=\left(\frac{k}{2}\right)^{\frac{2}{3}}(\xi-\eta)^{2} \\
& q=\left(\frac{k}{2}\right)^{\frac{1}{3}}\left(\xi-\frac{\pi}{2}\right)
\end{aligned}
$$

and we consider the following values of $\xi$ and $\eta$

and

$$
\begin{aligned}
& \xi=\xi_{1}+2 \pi m, \\
& \eta=\eta_{1}+2 \pi m
\end{aligned}
$$

$$
\begin{aligned}
& \xi=\xi_{2}+2 \pi m, \\
& \eta=\eta_{2}+2 \pi m .
\end{aligned}
$$

If we add up all possible modes, respectively, we get the following solution in the region of convergence of the series

$$
\begin{aligned}
& \tilde{\varphi}_{d, \text { tot }}=-i \pi^{\frac{1}{2}} \exp \left\{i k\left(\xi_{1}-\frac{\pi}{2}\right)-i \frac{2}{3} p_{1}^{\frac{3}{2}}\right\} \times \\
& \times \sum_{s=0}^{\infty} e^{i t_{s} q_{1}} \frac{w_{1}\left(t_{s}-p_{1}\right)}{\left\{w_{1}^{\prime}\left(t_{s}\right)\right\}^{2}}\left[1-\exp \left\{2 i k \pi+2 i\left(\frac{k}{2}\right)^{\frac{1}{3}} t_{s} \pi\right\}\right]^{-1}+ \\
& -i \pi^{\frac{1}{2}} \exp \left\{i k\left(\xi_{2}-\frac{\pi}{2}\right)-i \frac{2}{3} p_{2}^{\frac{3}{2}}\right\} \times \\
& \times \sum_{s=0}^{\infty} e^{i t_{s} q_{2}} \frac{w_{1}\left(t_{s}-p_{2}\right)}{\left\{w_{1}^{\prime}\left(t_{s}\right)\right\}^{2}}\left[1-\exp \left\{2 i k \pi+2 i\left(\frac{k}{2}\right)^{\frac{1}{3}} t_{s} \pi\right\}\right]^{-1}
\end{aligned}
$$


Near the shadow boundary where $\eta_{1} \approx \frac{1}{2} \pi$ we have the solution

$$
\begin{aligned}
& \tilde{\varphi}_{d, \text { tot }}=\frac{i}{4 \pi^{\frac{1}{2}}} \exp \left\{i k\left(\xi_{1}-\frac{\pi}{2}\right)-i \frac{2}{3} p_{1}^{\frac{3}{2}}\right\} \times \\
& \times \int_{C} e^{i t q_{1}}\left\{w_{2}\left(t-p_{1}\right)-\frac{w_{2}(t)}{w_{1}(t)} w_{1}\left(t-p_{1}\right)\right\} \mathrm{d} t+ \\
& -i \pi^{\frac{1}{2}} \exp \left\{i k\left(\xi_{1}+\frac{3 \pi}{2}\right)-i \frac{2}{3} p_{1}^{\frac{3}{2}}\right\} \times \\
& \times \sum_{s=0}^{\infty} e^{i t_{s} q_{1}} \frac{w_{1}\left(t_{s}-p_{1}\right)}{\left\{w_{1}^{\prime}\left(t_{s}\right)\right\}^{2}}\left[1-\exp \left\{2 i k \pi+2 i\left(\frac{k}{2}\right)^{\frac{1}{3}} t_{s} \pi\right\}\right]^{-1}+ \\
& -i \pi^{\frac{1}{2}} \exp \left\{i k\left(\xi_{2}-\frac{\pi}{2}\right)-i \frac{2}{3} p_{2}^{\frac{3}{2}}\right\} \times \\
& \times \sum_{s=0}^{\infty} e^{i t_{s} q_{2}} \frac{w_{1}\left(t_{s}-p_{2}\right)}{\left\{w_{1}^{\prime}\left(t_{s}\right)\right\}^{2}}\left[1-\exp \left\{2 i k \pi+2 i\left(\frac{k}{2}\right)^{\frac{1}{3}} t_{s} \pi\right\}\right]^{-1}
\end{aligned}
$$

with

$$
q_{1}^{\prime}=\left(\frac{k}{2}\right)^{\frac{1}{3}}\left(\xi_{1}+\frac{3 \pi}{2}\right)
$$

IV The region near the axis of symmetry we discussed in section 6

We notice that

and

$$
\xi_{1} \approx \xi_{2}=\xi
$$

$$
\eta_{1} \approx \eta_{2}=\eta
$$

and use the notation

$$
\delta=k\{\sin \eta+(\xi-\eta) \cos \eta\} .
$$

We add up all possible modes and arrive at the solution

$$
\begin{aligned}
& \tilde{\varphi}_{d, \text { tot }}=\left(\frac{k}{2}\right)^{\frac{1}{3}} \frac{\pi}{\sqrt{\xi}-\eta} \exp \left\{i k\left(\xi-\frac{\pi}{2}\right)\right\}(\sin \eta \cos \eta)^{\frac{1}{2}} \times \\
& \times\left\{\exp (-i \delta \cos \eta) H_{0}^{(1)}(\delta \cos \eta)+\exp (i \delta \cos \eta) H_{0}^{(2)}(\delta \cos \eta)\right\} \times \\
& \times \sum_{s=0}^{\infty} \frac{\exp \left\{i\left(\frac{k}{2}\right)^{\frac{1}{3}} t_{s}\left(\eta-\frac{\pi}{2}\right)\right\}}{\left\{w_{1}^{\prime}\left(t_{s}\right)\right\}^{2}}\left[1-\exp \left\{2 i k \pi+2 i\left(\frac{k}{2}\right)^{\frac{1}{3}} t_{s} \pi\right\}\right]^{-1} .
\end{aligned}
$$


For small values of $\xi-\eta$ we have region $\mathrm{V}$.

With

$$
\begin{aligned}
& p=\left(\frac{k}{2}\right)^{\frac{2}{3}}(\xi-\eta)^{2} \\
& q=\left(\frac{k}{2}\right)^{\frac{1}{3}}\left(\xi-\frac{\pi}{2}\right)
\end{aligned}
$$

we get the solution

$$
\begin{aligned}
& \tilde{\varphi}_{d, \text { tot }}=\pi \exp \left\{i k\left(\xi-\frac{\pi}{2}\right)-i \frac{2}{3} p^{\frac{3}{2}}\right\}(\sin \eta \cos \eta)^{\frac{1}{2}} \times \\
& \times\left\{\exp (-i \delta \cos \eta) H_{0}^{(1)}(\delta \cos \eta)+\exp (i \delta \cos \eta) H_{0}^{(2)}(\delta \cos \eta)\right\} \times \\
& \times \sum_{s=0}^{\infty} e^{i t_{s} q} \frac{w_{1}\left(t_{s}-p\right)}{\left\{w_{1}^{\prime}\left(t_{s}\right)\right\}^{2}}\left[1-\exp \left\{2 i k \pi+2 i\left(\frac{k}{2}\right)^{\frac{1}{3}} t_{s} \pi\right\}\right]^{-1} .
\end{aligned}
$$

It can be made clear that $(7,6)$ is an asymptotic solution of the Helmholtz equation, though we have derived $(7,6)$ from the matching principle.

\section{ASYMPTOTIC BEHAVIOUR IN THE LIT REGION}

In the preceding sections we discussed the asymptotic solution of the Helmholtz equation in the shadow region of the sphere. We will now investigate the behaviour of $\tilde{\varphi}$ in the lit region.

In the region far from the shadow boundary, in an arbitrary point $\mathrm{P}$ three kinds of rays will contribute to the asymptotic solution of the Helmholtz equation.

First of all we have the incoming and the reflected rays. The incoming ray is given and the reflected ray can be determined by laws of geometrical optics and is known [16]. A contribution is also given by the creeping waves which radiate the diffracted rays. Hence we get the following solution

$$
\tilde{\varphi}_{\text {tot }}=\tilde{\varphi}_{\text {inc }}+\tilde{\varphi}_{\text {refl }}+\tilde{\varphi}_{d, \text { tot }}
$$

where $\tilde{\varphi}_{d, \text { tot }}$ is given in $(7,1)$.

We will meet a complication, if we take the point $\mathrm{P}$ near the axis of symmetry. It is obvious that instead of $(7,1)$ we must take $(7,5)$ or $(7,6)$ as $\tilde{\varphi}_{d, \text { tot }}$. 


\section{SCATTERING OF A SPHERICAL WAVE BY A SPHERE}

\section{ASYMPTOTIC EXPANSION IN THE SHADOW REGION}

We will now discuss the field of a spherical wave scattered by a sphere. As in the preceding sections we are particularly interested in the asymptotic behaviour of the wave function for large values of the frequency. The solution method to be used is the same as before, in the case of scattering of the plane wave.

We consider a sphere with unit radius and three-dimensional source at finite distance $\left|\mathbf{r}_{0}\right|$ to its centre. Therefore the incoming wave is of the form

$$
\tilde{\varphi}_{\text {inc }}=\frac{\exp \left\{i k\left|\mathbf{r}-\mathbf{r}_{0}\right|\right\}}{\left|\mathbf{r}-\mathbf{r}_{0}\right|}
$$

where $\mathbf{r}$ represents the position vector of the observation point.

We introduce the same coordinates $\xi, \eta$ as in section 2 and assume that the incoming rays are tangent to the surface of the sphere in $\eta=\eta_{0}=\arccos \left\{\left|\mathbf{r}_{0}\right|^{-1}\right\}$, where the amplitude is equal to $\left(\operatorname{tg} \eta_{0}\right)^{-1}$.

The boundary condition implies that the wave function $\tilde{\varphi}$ is equal to zero. At infinity we require $\tilde{\varphi}$ to satisfy the radiation condition. On the shadow boundary we require a continuous solution and therefore the solution of the lit region and the one in the shadow region must be equal. In the lit region we have a solution of the form

$$
\tilde{\varphi}=\tilde{\varphi}_{\mathrm{inc}}+\tilde{\varphi}_{\mathrm{refl}}+\bar{\varphi}_{d} \text {. }
$$

On the shadow boundary we have $\tilde{\varphi}_{\text {refl }}=0$ and $\bar{\varphi}_{d}$ asymptotically zero, so the solution of the shadow region $\tilde{\varphi}_{d}$ becomes equal $\tilde{\varphi}_{\text {inc }}$ on the shadow boundary at finite distance from the sphere.

We determine the solution in the shadow region in the same way as we did in the 'plane' case. We start in the region near the sphere and near the shadow boundary, where $(\xi-\eta) \approx 0$ and $\eta \approx \eta_{0}$.

We introduce

with

$$
\begin{aligned}
& \alpha=k^{\frac{1}{3}}\left(\xi-\eta_{0}\right), \\
& \beta=k^{\frac{1}{3}}\left(\eta-\eta_{0}\right)
\end{aligned}
$$

$$
\begin{aligned}
& \beta<\alpha<\infty, \\
& 0<\beta<\infty .
\end{aligned}
$$


The power of $k$ in $(9,1)$ is determined in the same way as in section 3 . We also introduce

$$
\tilde{\varphi}_{d}=\exp \left\{i k\left(\xi-\xi_{0}\right)\right\} k^{r_{5}} \sum_{n=0}^{\infty} k^{-\frac{n}{3}} \varphi_{n}
$$

Only the first term of the series will be determined and must be a solution of the equation

$$
\frac{1}{\alpha-\beta} \frac{\partial}{\partial \beta} \frac{1}{\alpha-\beta} \frac{\partial \varphi_{0}}{\partial \beta}+2 i \frac{\partial \varphi_{0}}{\partial \alpha}+\frac{i \varphi_{0}}{\alpha-\beta}=0
$$

We follow the same procedure as in the previous chapter and introduce

$$
\begin{aligned}
& \chi=\varphi_{0} \exp \left\{\frac{i(\alpha-\beta)^{3}}{3}\right\} \\
& p=2^{-\frac{2}{3}}(\alpha-\beta)^{2}=\left(\frac{k}{2}\right)^{\frac{2}{3}}(\xi-\eta)^{2} \\
& q=2^{-\frac{1}{3}} \alpha \quad=\left(\frac{k}{2}\right)^{\frac{1}{3}}\left(\xi-\eta_{0}\right)
\end{aligned}
$$

where the function $\chi$ has to be a solution of the equation

$$
\frac{\partial^{2} \chi}{\partial p^{2}}+i \frac{\partial \chi}{\partial q}+p \chi=0
$$

with the boundary condition

$$
\chi=0, \quad \text { if } \quad p=0
$$

and 'shadow' condition like we discussed earlier in this section.

In the same way as before these considerations lead to the solution

where

$$
\varphi_{0}=\exp \left(-i \frac{2}{3} p^{\frac{3}{2}}\right) \int_{C} e^{i t q} F^{\prime}(t)\left\{v(t-p)-\frac{v(t)}{w_{1}(t)} w_{1}(t-p)\right\} d t
$$

$$
w_{1}(t)=u(t)+i v(t)
$$

so $v(t)$ is the imaginary part of $w_{1}(t)$ for real $t$. The contour $C$ is the same as before.

This solution satisfies the boundary condition and is valid near the sphere. The unknown function $F(t)$ still has to be determined. This is done by the condition 
$\tilde{\varphi}_{d}=\tilde{\varphi}_{\text {inc }}$ if $\eta=\eta_{0}$ and $\xi-\eta$ being finite and the solution symmetric with respect to the source and the observation point, if they are both at finite distance from the sphere. We therefore express the coordinates of the source in $p$ and $q$ coordinates $\left(p_{0}, q_{0}\right)$.

If the distance to the sphere is finite, then $p$ and $q$ tend to infinity, so we must obtain the solution for large values of the coordinates $p$ and $q$ first. This solution results from $(2,12)$ and has the form

$$
\tilde{\varphi}_{d} \approx \frac{\exp \left\{i k\left(\xi-\xi_{0}\right)\right\} k^{r_{5}} \varphi_{0}}{\{\operatorname{tg} \eta+(\xi-\eta)\}^{\frac{1}{2}}}
$$

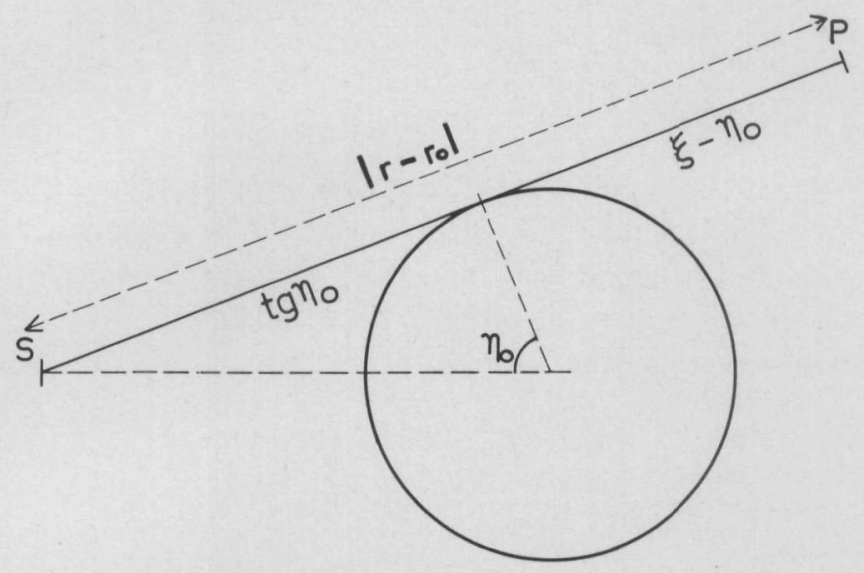

Fig. 4

If $\eta$ tends to $\eta_{0}$ we notice that the denominator is equal to $\left|\mathbf{r}-\mathbf{r}_{0}\right|^{\frac{1}{2}}$ which is symmetric in $\mathbf{r}$ and $\mathbf{r}_{0}$ (Fig. 4).

If we choose $F(t)$ equal to $A \exp \left[-i t q_{0}-i_{3}^{2} p_{0}^{\frac{3}{2}}\right] w_{1}\left(t-p_{0}\right)$, then in the limit case we get a symmetric function and we can make $\tilde{\varphi}_{d}$ equal $t_{o} \tilde{\varphi}_{\text {inc }}$ by the proper choice of $A$ and $r_{5}$.

The asymptotic solution which we have to expand for large values of $p, q, p_{0}, q_{0}$ follows from $(9,6)$ and $(9,7)$

$$
\begin{aligned}
\tilde{\varphi}_{d} & \approx \frac{A k^{r_{5}} \exp \left\{i k\left(\xi-\xi_{0}\right)-i \frac{2}{3}\left(p^{\frac{3}{2}}+p_{0}^{\frac{3}{3}}\right)\right\}}{\{\operatorname{tg} \eta+(\xi-\eta)\}^{\frac{1}{2}}} \times \\
& \times \int_{C} e^{i t\left(q-q_{0}\right)} w_{1}\left(t-p_{0}\right)\left\{v(t-p)-\frac{v(t)}{w_{1}(t)} w_{1}(t-p)\right\} d t .
\end{aligned}
$$

As we stated before this solution should be equal to $\tilde{\varphi}_{\text {inc }}$ on the shadow boundary at 
finite distance to the sphere and we get by means of the method of steepest descent (Appendix) and putting $\eta=\eta_{0}$

$$
\begin{aligned}
\tilde{\varphi}_{d} & \approx \frac{2 A k^{r_{5}}\left(\frac{k}{2}\right)^{-\frac{1}{6}} \pi^{\frac{1}{2}} \exp \left\{i k\left(\zeta-\xi_{0}\right)+\frac{\pi i}{4}\right\}}{\operatorname{tg} \eta_{0}+\xi-\eta_{0}}= \\
& =\tilde{\varphi}_{\mathrm{inc}}=\frac{\exp \left\{i k\left(\xi-\xi_{0}\right)\right\}}{\operatorname{tg} \eta_{0}+\xi-\eta_{0}} .
\end{aligned}
$$

So we find

$$
r_{5}=\frac{1}{6}, \quad A=\frac{2^{-\frac{1}{6}} e^{-\frac{\pi i}{4}}}{2 \pi^{\frac{1}{2}}}
$$

In this way we constructed a solution in the region near the sphere and the shadow boundary. We only need formula $(9,8)$ in the region where $p$ and $q$ are of the same order as $p_{0}$ and $q_{0}$. In the region near the sphere the order is different and we can expand $(9,8)$ for large values of $p_{0}, q_{0}$ with $p, q$ being finite.

We use the asymptotic expansion of $w_{1}\left(t-p_{0}\right)$ for large values of $p_{0}$ which states

$$
w_{1}\left(t-p_{0}\right)=p_{0}^{-\frac{1}{4}} \exp \left\{i\left(\frac{2}{3} p_{0}^{\frac{3}{2}}-t p_{0}^{\frac{1}{2}}+\frac{t^{2} p_{0}^{-\frac{1}{2}}}{4}+\frac{\pi}{4}\right)\right\}
$$

Taking into consideration that

$$
\begin{aligned}
& p_{0}^{\frac{1}{2}}=q_{0} \\
& p_{0}=\left(\frac{k}{2}\right)^{\frac{2}{3}} \operatorname{tg}^{2} \eta_{0} \text { and } p_{0}>p
\end{aligned}
$$

we get the following expansion of the field

$$
\begin{aligned}
\tilde{\varphi}_{d} & \approx \frac{\exp \left\{i k\left(\xi-\xi_{0}\right)-i \frac{2}{3} p^{\frac{3}{2}}\right\}}{2\left[\pi \operatorname{tg} \eta_{0}\{\operatorname{tg} \eta+(\xi-\eta)\}\right]^{\frac{1}{2}}} \times \\
& \times \int_{C} e^{i t q}\left\{v(t-p)-\frac{v(t)}{w_{1}(t)} w_{1}(t-p)\right\} d t
\end{aligned}
$$

This result is not only a solution in the region near the shadow boundary. We also use this one as a solution at finite distance from this boundary. This can be derived 
in the same way as we did in section 4 and it is clear that we can take the sum of residues as a solution in this region

$$
\begin{aligned}
\tilde{\varphi}_{d} & \approx \frac{-\pi i \exp \left\{i k\left(\xi-\xi_{0}\right)-i \frac{2}{3} p^{\frac{3}{2}}\right\}}{\left[\pi \operatorname{tg} \eta_{0}\{\operatorname{tg} \eta+(\xi-\eta)\}\right]^{\frac{1}{2}}} \times \\
& \times \sum_{s=0}^{\infty} e^{i t_{s} q} \frac{w_{1}\left(t_{s}-p\right)}{\left\{w_{1}^{\prime}\left(t_{s}\right)\right\}^{2}}
\end{aligned}
$$

We used the relation between $v(t)$ and $w(t)$ which resulted from the Wronski determinant

$$
w_{1}^{\prime}(t) v(t)-w_{1}(t) v^{\prime}(t)=1
$$

and, in the zeroes $t_{s}$ of the function $w_{1}(t)$ this leads to

$$
v\left(t_{s}\right)=\frac{1}{w_{1}^{\prime}\left(t_{s}\right)}
$$

Solution $(9,11)$ is valid at small distance from the sphere. At finite distance we expand $(9,11)$ for large values of $p$ which yields

$$
\begin{aligned}
\tilde{\varphi}_{d} & \approx \frac{\pi\left(\frac{k}{2}\right)^{-\frac{1}{6}} \exp \left\{i k\left(\xi-\xi_{0}\right)-\frac{\pi i}{4}\right\}}{\left[\pi \operatorname{tg} \eta_{0}(\xi-\eta)\{\operatorname{tg} \eta+(\xi-\eta)\}\right]^{\frac{1}{2}}} \times \\
& \times \sum_{s=0}^{\infty} \frac{\exp \left\{i\left(\frac{k}{2}\right)^{\frac{1}{3}} t_{s}\left(\eta-\eta_{0}\right)\right\}}{\left\{w_{1}^{\prime}\left(t_{s}\right)\right\}^{2}} .
\end{aligned}
$$

Bearing in mind the values of $t_{s}$ on the line $\varrho e^{\frac{1}{3} \pi i}$ we notice that for rather large $\eta-\eta_{0}$ this solution is asymptotically equal to zero. Actually we are now able to give the complete shadow solution but for the region near the caustic which in our case is the line $\operatorname{tg} \eta+(\xi-\eta)=0$, viz. the axis of symmetry. The derivation in this region can be carried out in the same way as in section 6 by introducing the new variable

$$
\delta=k\{\sin \eta+(\xi-\eta) \cos \eta\}
$$

At finite distance from the sphere we arrive at a solution which is a continuation of $(9,12)$ 


$$
\begin{gathered}
\tilde{\varphi}_{d} \approx \frac{\pi i\left(\frac{k}{2}\right)^{\frac{1}{3}} \cos \eta \exp \left\{i k\left(\xi-\xi_{0}\right)-i \delta \cos \eta\right\}}{\left\{\operatorname{tg} \eta_{0}(\xi-\eta)\right\}^{\frac{1}{2}}} \times \\
\times H_{0}^{(1)}(\delta \cos \eta) \sum_{s=0}^{\infty} \frac{\exp \left\{i\left(\frac{k}{2}\right)^{\frac{1}{3}} t_{s}\left(\eta-\eta_{0}\right)\right\}}{\left\{w_{1}^{\prime}\left(t_{s}\right)\right\}^{2}}
\end{gathered}
$$

Solution $(9,13)$ is singular on the sphere $\xi=\eta$. Hence we determine a solution on the axis of symmetry near the sphere. This solution must be a continuation of the one near the sphere and it is obvious that an asymptotic expansion in this region will be obtained by stretching $\xi-\eta$ as well.

However, we will compare the two solutions $(9,13)$ and $(9,11)$ and in this way arrive at the solution near the sphere and the axis of symmetry

$$
\begin{aligned}
\tilde{\varphi}_{d} & \approx \frac{\pi\left(\frac{k}{2}\right)^{\frac{1}{2}} e^{\frac{\pi i}{4}} \cos \eta \exp \left\{i k\left(\xi-\xi_{0}\right)-i \frac{2}{3} p^{\frac{3}{2}}-i \delta \cos \eta\right\}}{\operatorname{tg}^{\frac{1}{2}} \eta_{0}} \times \\
& \times H_{0}^{(1)}(\delta \cos \eta) \sum_{s=0}^{\infty} e^{i t_{s} q} \frac{w_{1}\left(t_{s}-p\right)}{\left\{w_{1}^{\prime}\left(t_{s}\right)\right\}^{2}}
\end{aligned}
$$

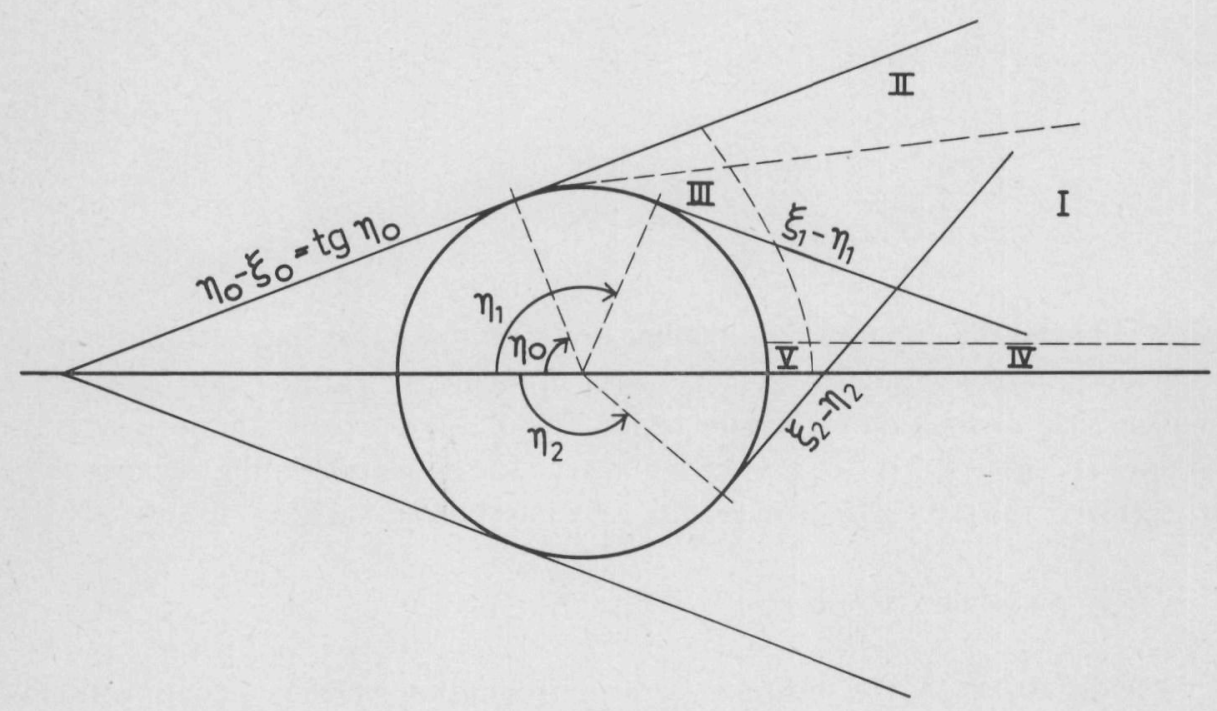

Fig. 5 
In all these solutions we used the coordinates

$$
\begin{aligned}
& p=\left(\frac{k}{2}\right)^{\frac{2}{3}}(\xi-\eta)^{2} \\
& q=\left(\frac{k}{2}\right)^{\frac{1}{3}}\left(\xi-\eta_{0}\right)
\end{aligned}
$$

Finally we can give the complete solution as follows

I The region where

and

$$
\begin{array}{ll}
\eta_{1} \gg \eta_{0}, & \xi_{1} \gg \eta_{1}, \\
\eta_{2} \gg \eta_{0}, & \xi_{2} \gg \eta_{2}
\end{array}
$$

We find

$$
\sin \eta_{1,2}+\left(\xi_{1,2}-\eta_{1,2}\right) \cos \eta_{1,2}=O(1)
$$

$$
\begin{aligned}
& \tilde{\varphi}_{d, \text { tot }} \approx \frac{\pi\left(\frac{k}{2}\right)^{-\frac{1}{6}} \exp \left\{i k\left(\xi_{1}-\xi_{0}\right)-\frac{\pi i}{4}\right\}}{\left[\pi \operatorname{tg} \eta_{0}\left(\xi_{1}-\eta_{1}\right)\left\{\operatorname{tg} \eta_{1}+\left(\xi_{1}-\eta_{1}\right)\right\}\right]^{\frac{1}{2}}} \times \\
& \times \sum_{s=0}^{\infty} \frac{\exp \left\{i\left(\frac{k}{2}\right)^{\frac{1}{3}} t_{s}\left(\eta_{1}-\eta_{0}\right)\right\}}{\left\{w_{1}^{\prime}\left(t_{s}\right)\right\}^{2}}\left[1-\exp \left\{2 k \pi i+2\left(\frac{k}{2}\right)^{\frac{1}{3}} t_{s} \pi i\right\}\right]^{-1}+ \\
& +\frac{\pi\left(\frac{k}{2}\right)^{-\frac{1}{6}} \exp \left\{i k\left(\xi_{2}-\xi_{0}\right)-\frac{\pi i}{4}\right\}}{\left[\pi \operatorname{tg} \eta_{0}\left(\xi_{2}-\eta_{2}\right)\left\{\operatorname{tg} \eta_{2}+\left(\xi_{2}-\eta_{2}\right)\right\}\right]^{\frac{1}{2}}} \times \\
& \times \sum_{s=0}^{\infty} \frac{\exp \left\{i\left(\frac{k}{2}\right)^{\frac{1}{3}} t_{s}\left(\eta_{2}-\eta_{0}\right)\right\}}{\left\{w_{1}^{\prime}\left(t_{s}\right)\right\}^{2}}\left[1-\exp \left\{2 k \pi i+2\left(\frac{k}{2}\right)^{\frac{1}{3}} t_{s} \pi i\right\}\right]^{-1}
\end{aligned}
$$

We use this solution in the region where the summation over $s$ is rapidly convergent when $\eta_{1,2}-\eta_{0}$ is finite. Obviously we must come to an other solution, if the summation is not rapidly convergent. This is the case in region II.

\section{The region where}

$$
\begin{array}{ll}
\eta_{1} \approx \eta_{0}, & \xi_{1} \gg \eta_{1}, \\
\eta_{2} \gg \eta_{0}, & \xi_{2} \gg \eta_{2} .
\end{array}
$$


In this region we give the solution of the ray which corresponds with $\xi_{1}, \eta_{1}$ in integral form and the other contribution can be totalled up as before

$$
\begin{aligned}
& \tilde{\varphi}_{d, \text { tot }} \approx \frac{\exp \left\{i k\left(\xi_{1}-\xi_{0}\right)-i \frac{2}{3} p_{1}^{\frac{3}{2}}\right\}}{2\left[\pi \operatorname{tg} \eta_{0}\left\{\operatorname{tg} \eta_{1}+\left(\xi_{1}-\eta_{1}\right)\right\}\right]^{\frac{1}{2}}} \times \\
& \times \int_{C} e^{i t q_{1}}\left\{v\left(t-p_{1}\right)-\frac{v(t)}{w_{1}(t)} w_{1}\left(t-p_{1}\right)\right\} \mathrm{d} t+ \\
& +\frac{\pi\left(\frac{k}{2}\right)^{-\frac{1}{6}} \exp \left\{i k\left(\xi_{1}-\xi_{0}+2 \pi\right)-\frac{\pi i}{4}\right\}}{\left[\pi \operatorname{tg} \eta_{0}\left(\xi_{1}-\eta_{1}\right)\left\{\operatorname{tg} \eta_{1}+\left(\xi_{1}-\eta_{1}\right)\right\}\right]^{\frac{1}{2}}} \times \\
& \times \sum_{s=0}^{\infty} \frac{\exp \left\{i\left(\frac{k}{2}\right)^{\frac{1}{3}} t_{s}\left(\eta_{1}-\eta_{0}+2 \pi\right)\right\}}{\left\{w_{1}^{\prime}\left(t_{s}\right)\right\}^{2}}\left[1-\exp \left\{2 k \pi i+2\left(\frac{k}{2}\right)^{\frac{1}{3}} t_{s} \pi i\right\}\right]^{-1}+ \\
& +\frac{\pi\left(\frac{k}{2}\right)^{-\frac{1}{6}}}{\left[\pi \operatorname{tg} \eta_{0}\left(\xi_{2}-\eta_{2}\right)\left\{\operatorname{tg} \eta_{2}+\left(\xi_{2}-\eta_{2}\right)\right\}\right]^{\frac{1}{2}}} \times \\
& \times \sum_{s=0}^{\infty} \frac{\exp \left\{i\left(\frac{k}{2}\right)^{\frac{1}{3}} t_{s}\left(\eta_{2}-\eta_{0}\right)\right\}}{\left\{w_{1}^{\prime}\left(t_{s}\right)\right\}^{2}}\left[1-\exp \left\{2 k \pi i+2\left(\frac{k}{2}\right)^{\frac{1}{3}} t_{s} \pi i\right\}\right]^{-1}
\end{aligned}
$$

For large values of $p_{1}$ and $q_{1}$ the integral in the formula must be changed in an integral of the form $(9,8)$ and the first part of the solution is as follows

$$
\begin{aligned}
& \frac{\left(\frac{k}{2}\right)^{\frac{1}{0}} \exp \left\{i k\left(\xi_{1}-\xi_{0}\right)-i \frac{2}{3}\left(p_{1}^{\frac{3}{2}}+p_{0}^{\frac{3}{2}}\right)-\frac{\pi i}{4}\right\}}{2\left[\pi\left\{\operatorname{tg} \eta_{1}+\left(\xi_{1}-\eta_{1}\right)\right\}\right]^{\frac{1}{2}}} \times \\
& \times \int_{C} e^{i t\left(q-q_{0}\right)} w_{1}\left(t-p_{0}\right)\left\{v\left(t-p_{1}\right)-\frac{v(t)}{w_{1}(t)} w_{1}\left(t-p_{1}\right)\right\} \mathrm{d} t .
\end{aligned}
$$

This solution is valid if $q_{0}>q_{1}$ and $q_{0}$ being large, if $q_{1}$ tends to $q_{0}$, we must expand the integral by means of steepest descent (Appendix) which leaves only

$$
\tilde{\varphi}_{\text {inc }} \text {. }
$$

This solution is valid at finite distance from the sphere. 
III The region where

and

$$
\begin{aligned}
& \xi_{1} \approx \eta_{1}, \\
& \xi_{2} \approx \eta_{2}
\end{aligned}
$$

$$
\sin \eta_{1,2}+\left(\xi_{1,2}-\eta_{1,2}\right) \cos \eta_{1,2}=O(1) .
$$

In this region is $p_{0} \gg p_{1,2}, q_{0} \gg q_{1,2}$ and we get the result

$$
\begin{aligned}
& \tilde{\varphi}_{d, \text { tot }} \approx \frac{-\pi i \exp \left\{i k\left(\xi_{1}-\xi_{0}\right)-i \frac{2}{3} p_{1}^{\frac{3}{2}}\right\}}{\left(\pi \operatorname{tg} \eta_{0} \operatorname{tg} \eta_{1}\right)^{\frac{1}{2}}} \times \\
& \times \sum_{s=0}^{\infty} e^{i t_{s} q_{1}} \frac{w_{1}\left(t_{s}-p_{1}\right)}{\left\{w_{1}^{\prime}\left(t_{s}\right)\right\}^{2}}\left[1-\exp \left\{2 k \pi i+2\left(\frac{k}{2}\right)^{\frac{1}{3}} t_{s} \pi i\right\}\right]^{-1}+ \\
& -\frac{\pi i \exp \left\{i k\left(\xi_{2}-\xi_{0}\right)-i \frac{2}{3} p_{2}^{\frac{3}{2}}\right\}}{\left(\pi \operatorname{tg} \eta_{0} \operatorname{tg} \eta_{2}\right)^{\frac{1}{2}}} \times \\
& \times \sum_{s=0}^{\infty} e^{i t_{s} q_{2}} \frac{w_{1}\left(t_{s}-p_{2}\right)}{\left\{w_{1}^{\prime}\left(t_{s}\right)\right\}^{2}}\left[1-\exp \left\{2 k \pi i+2\left(\frac{k}{2}\right)^{\frac{1}{3}} t_{s} \pi i\right\}\right]^{-1}
\end{aligned}
$$

Near the shadow boundary $\eta_{1} \approx \eta_{0}$ we have the solution

$$
\begin{aligned}
& \tilde{\varphi}_{d, \text { tot }} \approx \frac{\exp \left\{i k\left(\xi_{1}-\xi_{0}\right)-i \frac{2}{3} p_{1}^{\frac{3}{2}}\right\}}{2\left(\pi \operatorname{tg} \eta_{0}\right)^{\frac{1}{2}}} \times \\
& \times \int_{C} e^{i t q_{1}}\left\{v\left(t-p_{1}\right)-\frac{v(t)}{w_{1}(t)} w_{1}\left(t-p_{1}\right)\right\} \mathrm{d} t+ \\
& +\frac{-\pi i \exp \left\{i k\left(\xi_{1}-\xi_{0}+2 \pi\right)-i \frac{2}{3} p_{1}^{\frac{3}{2}}\right\}}{\left(\pi \operatorname{tg} \eta_{0} \operatorname{tg} \eta_{1}\right)^{\frac{1}{2}}} \times \\
& \times \sum_{s=0}^{\infty} e^{i t_{s} q_{1}} \frac{w_{1}\left(t_{s}-p_{1}\right)}{\left\{w_{1}^{\prime}\left(t_{s}\right)\right\}^{2}}\left[1-\exp \left\{2 k \pi i+2\left(\frac{k}{2}\right)^{\frac{1}{3}} t_{s} \pi i\right\}\right]^{-1}+ \\
& +\frac{-\pi i \exp \left\{i k\left(\xi_{2}-\xi_{0}\right)-i \frac{2}{3} p_{2}^{\frac{3}{2}}\right\}}{\left(\pi \operatorname{tg} \eta_{0} \operatorname{tg} \eta_{2}\right)^{\frac{1}{2}}} \times \\
& \times \sum_{s=0}^{\infty} e^{i t_{s} q_{2}} \frac{w_{1}\left(t_{s}-p_{2}\right)}{\left\{w_{1}^{\prime}\left(t_{s}\right)\right\}^{2}}\left[1-\exp \left\{2 k \pi i+2\left(\frac{k}{2}\right)^{\frac{1}{3}} t_{s} \pi i\right\}\right]^{-1}
\end{aligned}
$$


where

$$
q_{1}^{\prime}=\left(\frac{k}{2}\right)^{\frac{1}{3}}\left(\xi_{1}-\xi_{0}+2 \pi\right)
$$

All these solutions are valid, if the distance to the axis of symmetry (caustic) is finite.

IV The region where

$$
\begin{aligned}
& \xi_{1} \approx \xi_{2}=\xi, \\
& \eta_{1} \approx \eta_{2}=\eta
\end{aligned}
$$

and $\delta=k\{\sin \eta+(\xi-\eta) \cos \eta\}$ is finite.

We now make use of solution $(9,13)$ which yields in region $\xi \gg \eta$

$$
\begin{aligned}
& \tilde{\varphi}_{d, \text { tot }} \approx \frac{\pi i\left(\frac{k}{2}\right)^{\frac{1}{3}} \cos \eta}{\left\{\operatorname{tg} \eta_{0}(\xi-\eta)\right\}^{\frac{1}{2}}} \exp \left\{i k\left(\xi-\xi_{0}\right)\right\} \times \\
& \times\left\{\exp (-i \delta \cos \eta) H_{0}^{(1)}(\delta \cos \eta)+\exp (i \delta \cos \eta) H_{0}^{(2)}(\delta \cos \eta)\right\} \times \\
& \times \sum_{s=0}^{\infty} \frac{\exp \left\{i\left(\frac{k}{2}\right)^{\frac{1}{3}} t_{s}\left(\eta-\eta_{0}\right)\right\}}{\left\{w_{1}^{\prime}\left(t_{s}\right)\right\}^{2}}\left[1-\exp \left\{2 k \pi i+2\left(\frac{k}{2}\right)^{\frac{1}{3}} t_{s} \pi i\right\}\right]^{-1}
\end{aligned}
$$

For small values of $\xi-\eta$ we come to region $\mathrm{V}$ and the solution

$$
\begin{aligned}
& \tilde{\varphi}_{d, \text { tot }} \approx \frac{\pi\left(\frac{k}{2}\right)^{\frac{1}{2}} \cos \eta}{\operatorname{tg}^{\frac{1}{2}} \eta_{0}} \exp \left\{i k\left(\xi-\xi_{0}\right)-i \frac{2}{3} p^{\frac{3}{2}}+\frac{\pi i}{4}\right\} \times \\
& \times\left\{\exp (-i \delta \cos \eta) H_{0}^{(1)}(\delta \cos \eta)+\exp (i \delta \cos \eta) H_{0}^{(2)}(\delta \cos \eta)\right\} \times \\
& \times \sum_{s=0}^{\infty} e^{i t_{s} q} \frac{w_{1}\left(t_{s}-p\right)}{\left\{w_{1}^{\prime}\left(t_{s}\right)\right\}^{2}}\left[1-\exp \left\{2 k \pi i+2\left(\frac{k}{2}\right)^{\frac{1}{3}} t_{s} \pi i\right\}\right]^{-1}
\end{aligned}
$$

This last formula completes the solution in the shadow region. We only treated the case where the source is at finite distance from the sphere. It is possible to arrive at solutions if $\operatorname{tg} \eta_{0}$ is small. This will cause practically no alteration in the formulas and they can easily be found. Attention should be paid to the fact that the region where $p$ and $p_{0}$ are of the same order is quite near the sphere, hence we must take integrals of the form $(9,8)$ instead of $(9,10)$ and we must supply residue expansions of $(9,8)$. 


\section{ASYMPTOTIC EXPANSION IN THE LIT REGION}

In the lit region we get the same kind of solution as discussed in section 8 . There is a region at finite distance from the shadow boundary where the field consists of a composition of the incident, reflected and the diffracted rays.

So we get

$$
\tilde{\varphi}_{d, \text { tot }} \approx \tilde{\varphi}_{\mathrm{inc}}+\tilde{\varphi}_{\mathrm{ref} 1}+\bar{\varphi}_{d}
$$

with $\bar{\varphi}_{d}$ of the form $(9,15)$. 


\section{DIFFRACTION OF WAVES BY AN ARBITRARY SMOOTH CONVEX OBJECT}

\section{DERIVATION OF THE ASYMPTOTIC EQUATION}

Here we investigate the three-dimensional diffraction of waves by a smooth convex object. Two cases are considered, viz. a plane and a spherical incident wave.

Although the object is the same, we must introduce a different coordinate system in both cases. We discuss only the field caused by the creeping rays. In section 1 we defined creeping rays as geodesic lines starting on the shadow boundary in the direction of the incident rays. We call these lines $u^{2}=$ constant. The arclength along these rays is defined by $u^{1}$ and the shadow boundary is $u^{1}=h\left(u^{2}\right)$. The coordinate lines, on the surface, $u^{1}=$ constant, are perpendicular to the geodesics. The surface is determined by the vector

$$
\begin{aligned}
x^{i}=x^{i}\left(u^{\alpha}\right), & i=1,2,3 \\
\alpha & =1,2
\end{aligned}
$$

and the line element on the surface by

$$
\mathrm{d} s^{2}=\mathrm{d} u^{1^{2}}+g \mathrm{~d} u^{2^{2}}
$$

with

$$
g_{i j}=\delta_{k l} \frac{\partial x^{k}}{\partial u^{i}} \frac{\partial x^{l}}{\partial u^{j}}, g_{11}=1, g_{12}=0 \text { and } g_{22}=g
$$

where

$$
\delta_{k l}=\left\{\begin{array}{lll}
1 & \text { if } & k=l \\
0 & \text { if } & k \neq l
\end{array}\right.
$$

The diffracted rays are tangentially to the geodesics and therefore we introduce the new coordinates $u^{1}, u^{2}$ and $u^{3}$ as follows

$$
z^{i}\left(u^{1}, u^{2}, u^{3}\right)=x^{i}\left(u^{1}, u^{2}\right)+\left(u^{3}-u^{1}\right) \frac{\partial x^{i}}{\partial u^{1}}
$$

where $z^{i}$ are the Cartesian coordinates of a point in space, which lies on a tangent to one of the geodesics considered. 
In the $u^{i}$ coordinates we derive the Laplace operator $\Delta$ which has the form

$$
\Delta=G^{i j}\left\{\frac{\partial^{2}}{\partial u^{i} \partial u^{j}}-\Gamma_{i j}^{k} \frac{\partial}{\partial u^{k}}\right\}
$$

$G^{i j}$ is the contravariant metric tensor and $\Gamma_{i j}^{k}$ the Christoffel symbol of the second kind.

First we derive the covariant metric tensor

$$
G_{i j}=\delta_{k l} \frac{\partial z^{k}}{\partial u^{i}} \frac{\partial z^{l}}{\partial u^{j}}
$$

We find

$$
\begin{aligned}
& G_{11}=\left(u^{3}-u^{1}\right)^{2} \delta_{i j} \frac{\partial^{2} x^{i}}{\partial u^{12}} \frac{\partial^{2} x^{j}}{\partial u^{12}} \\
& G_{12}=\left(u^{3}-u^{1}\right)^{2} \delta_{i j} \frac{\partial^{2} x^{i}}{\partial u^{12}} \frac{\partial^{2} x^{j}}{\partial u^{1} \partial u^{2}}, \\
& G_{22}=g+\left(u^{3}-u_{1}^{1}\right) \frac{\partial g}{\partial u^{1}}+\left(u^{3}-u^{1}\right)^{2} \delta_{i j} \frac{\partial^{2} x^{i}}{\partial u^{1} \partial u^{2}} \frac{\partial^{2} x^{j}}{\partial u^{1} \partial u^{2}}, \\
& G_{13}=G_{23}=0 \\
& G_{33}=1 .
\end{aligned}
$$

From $(11,2)$ follows that the unit vector $n_{i}$, normal to the surface, has the form

$$
\frac{\partial^{2} x^{i}}{\partial u^{12}}=\frac{1}{\varrho\left(u^{1}, u^{2}\right)} n_{i}
$$

with $\varrho\left(u^{1}, u^{2}\right)$ as the radius of curvature of the geodesic $u^{2}=$ constant. The determinant $G$ of the metric tensor is

$$
\begin{aligned}
G & =\frac{\left(u^{3}-u^{1}\right)^{2}}{\varrho^{2}}\left\{g+\left(u^{3}-u^{1}\right) \frac{\partial g}{\partial u^{1}}\right\}+ \\
& +\left(u^{3}-u^{1}\right)^{4}\left\{\frac{1}{\varrho^{2}} \delta_{i j} \frac{\partial^{2} x^{i}}{\partial u^{1} \partial u^{2}} \frac{\partial^{2} x^{j}}{\partial u^{1} \partial u^{2}}-\left(\delta_{i j} \frac{\partial^{2} x^{i}}{\partial u^{12}} \frac{\partial^{2} x^{j}}{\partial u^{1} \partial u^{2}}\right)^{2}\right\}
\end{aligned}
$$

and with $(11,2)$ we find

$$
G=\frac{\left(u^{3}-u^{1}\right)^{2}}{\varrho^{2}}\left\{g^{\frac{1}{2}}+\left(u^{3}-u^{1}\right) \frac{\partial g^{\frac{1}{2}}}{\partial u^{1}}\right\}^{2} .
$$


We introduce

and find

$$
R=\delta_{i j} \frac{\partial^{2} x^{i}}{\partial u^{12}} \frac{\partial^{2} x^{j}}{\partial u^{1} \partial u^{2}}
$$

$$
\begin{aligned}
& G^{11}=\frac{1}{G}\left[\left\{g^{\frac{1}{2}}+\left(u^{3}-u^{1}\right) \frac{\partial g^{\frac{1}{2}}}{\partial u^{1}}\right\}^{2}+\left(u^{3}-u^{1}\right)^{2} \varrho^{2} R^{2}\right] \\
& G^{12}=\frac{-1}{G}\left(u^{3}-u^{1}\right)^{2} R \\
& G^{22}=\frac{1}{G} \frac{\left(u^{3}-u^{1}\right)^{2}}{\varrho^{2}} \\
& G^{13}=G^{23}=0 \\
& G^{33}=1
\end{aligned}
$$

In section 1 we noticed the wave function being of the form

$$
\tilde{\varphi}_{d}=\varphi_{d} \exp \left\{i k\left(S_{0}+u^{3}\right)\right\}
$$

with $S_{0}=$ constant.

Introducing the same substitution here, we obtain the following form of the Helmholtz equation

$$
G^{i j}\left(\frac{\partial^{2} \varphi_{d}}{\partial u^{i} \partial u^{j}}-\Gamma_{i j}^{k} \frac{\partial \varphi_{d}}{\partial u^{k}}\right)+i k\left\{2 \frac{\partial \varphi_{d}}{\partial u^{3}}+\frac{\varphi_{d}}{u^{3}-u^{1}}+\frac{\varphi_{d} \frac{\partial g^{\frac{1}{2}}}{\partial u^{1}}}{g^{\frac{1}{2}}+\left(u^{3}-u^{1}\right) \frac{\partial g^{\frac{1}{2}}}{\partial u^{1}}}\right\}=0
$$

On the object we have the condition $\varphi_{d}=0$, at infinity we require the radiation condition and on the shadow boundary at finite distance from the object

$$
\tilde{\varphi}_{d}=\tilde{\varphi}_{\text {inc }}
$$

An asymptotic solution of $(11,9)$ can be found by equating the term with the highest power of $k$ to zero. This leads to an ordinary differential equation in $u^{3}$ with solution

$$
\varphi_{d} \approx \frac{F\left(u^{1}, u^{2}\right)}{\left[\left(u^{3}-u^{1}\right)\left\{g^{\frac{1}{2}}+\left(u^{3}-u^{1}\right) \frac{\partial g^{\frac{1}{2}}}{\partial u^{1}}\right\}\right]^{\frac{1}{2}}}
$$


where the function $F\left(u^{1}, u^{2}\right)$ only depends on $u^{1}$ and $u^{2}$. Solution $(11,10)$ is singular on the object where $u^{3}=u^{1}$ and on the surface where

$$
g^{\frac{1}{2}}+\left(u^{3}-u^{1}\right) \frac{\partial g^{\frac{1}{2}}}{\partial u^{1}}=0
$$

This surface we call a caustic surface.

In the case of the sphere the caustic is reduced to the axis of symmetry. In the last chapter we treat two problems without a caustic. In principle our method makes it possible to give asymptotic solutions near the caustic as well. In this thesis we only consider solutions valid at finite distance from the caustic.

We now apply the method of boundary layer expansions to find a solution valid near the object. We therefore stretch the coordinates near the object and the shadow boundary. The shadow boundary on the object is the given line $u^{1}=h\left(u^{2}\right)$. We introduce the new coordinates

$$
\begin{aligned}
& \alpha=k^{\frac{1}{3}}\left\{u^{3}-h\left(u^{2}\right)\right\}, \\
& \beta=k^{\frac{1}{3}}\left\{u^{1}-h\left(u^{2}\right)\right\} .
\end{aligned}
$$

The power $\frac{1}{3}$ of $k$ follows from the same reasoning as in the case of the sphere. Putting this in equation $(11,9)$ and equating the coefficient of the highest power of $k$ to zero we get a differential equation for the asymptotic solution

$$
\frac{\varrho^{2}}{\alpha-\beta} \frac{\partial}{\partial \beta} \frac{1}{\alpha-\beta} \frac{\partial \varphi_{d}}{\partial \beta}+2 i \frac{\partial \varphi_{d}}{\partial \alpha}+\frac{i \varphi_{d}}{\alpha-\beta}=0
$$

where we take for $\varrho$ the value of the radius of curvature on the shadow boundary on the surface $\varrho=\varrho\left\{h\left(u^{2}\right), u^{2}\right\}$.

Introducing the coordinates

$$
\begin{aligned}
& p=2^{-\frac{2}{3}} Q^{-\frac{4}{3}}(\alpha-\beta)^{2}, \\
& q=2^{-\frac{1}{3}} \varrho^{-\frac{2}{3}} \alpha
\end{aligned}
$$

and the new function $\chi$

$$
\chi=\varphi_{d} \exp \left(i \frac{2}{3} p^{\frac{3}{2}}\right)
$$

we arrive at the equation for $\chi$

$$
\frac{\partial^{2} \chi}{\partial p^{2}}+i \frac{\partial \chi}{\partial q}+p \chi=0
$$

with the boundary condition $\chi=0$, if $p=0$. 
The solution of this equation depends on $\tilde{\varphi}_{\text {inc }}$. We therefore consider different forms of the incident wave.

\section{THE INCIDENT WAVE IS PLANE}

Dealing with a plane incident wave we obtain a solution of $(11,12)$ of the form

$$
\chi=A \int_{C} e^{i t q}\left\{w_{2}(t-p)-\frac{w_{2}(t)}{w_{1}(t)} w_{1}(t-p)\right\} \mathrm{d} t
$$

where the contour $C$ is the same as before. This function $\chi$ determines the asymptotic solution near the shadow boundary and the object. To find the constant $A$ we use the condition on the shadow boundary, which states that at finite distance from the object the asymptotic solution tends to $\tilde{\varphi}_{\text {inc }}$. Therefore we continue $(12,1)$ in that region with the help of $(11,10)$ and get the solution

$$
\tilde{\varphi}_{d} \approx \frac{A \exp \left\{i k\left(S_{0}+u^{3}\right)-i \frac{2}{3} p^{\frac{3}{2}}\right\}}{\left\{g^{\frac{1}{2}}+\left(u^{3}-u^{1}\right) \frac{\partial g^{\frac{1}{2}}}{\partial u^{1}}\right\}^{\frac{1}{2}}} \int_{c}^{i t q}\left\{w_{2}(t-p)-\frac{w_{2}(t)}{w_{1}(t)} w_{1}(t-p)\right\} \mathrm{d} t
$$

We first determine the value of

$$
\varrho_{1}=\frac{g^{\frac{1}{2}}\left\{h\left(u^{2}\right), u^{2}\right\}}{\frac{\partial g^{\frac{1}{2}}}{\partial u^{1}}}
$$

In general, for a point source all tangent rays on the shadow boundary $u^{1}=h\left(u^{2}\right)$ are generated by this source. Hence we give the source $\bar{x}^{i}$ as a point on a tangent line

$$
\bar{x}^{i}=x^{i}\left\{h\left(u^{2}\right), u^{2}\right\}-r\left(u^{2}\right) \frac{\partial x^{i}}{\partial u^{1}} .
$$

The condition that $\bar{x}^{i}$ is in fact a fixed point for all rays, gives

$$
\mathrm{d} \bar{x}^{i}=0
$$

and therefore differentiation with respect to $u^{2}$ gives

$$
\left(\frac{\partial x^{i}}{\partial u^{1}} h_{u^{2}}+\frac{\partial x^{i}}{\partial u^{2}}\right)-r\left(\frac{\partial^{2} x^{i}}{\partial u^{12}} h_{u^{2}}+\frac{\partial^{2} x^{i}}{\partial u^{1} \partial u^{2}}\right)-r_{u^{2}} \frac{\partial x^{i}}{\partial u^{1}}=0
$$


Multiplication with $\partial x^{i} / \partial u^{2}$ and summing up over $i$ leads to

$$
r=\frac{g^{\frac{1}{2}}}{\frac{\partial g^{\frac{1}{2}}}{\partial u^{1}}}
$$

where we used the properties of the metric tensor of the surface. Therefore $\varrho_{1}$ is the distance from a point on the shadow boundary on the surface to the source.

In this case we are dealing with a plane incident wave, hence

$$
\varrho_{1}=\infty
$$

This leads to

$$
\frac{\partial g^{\frac{1}{2}}}{\partial u^{1}}=0
$$

on the shadow boundary. For large values of $p$ we get

$$
\tilde{\varphi}_{\text {inc }}=\frac{4 \pi^{\frac{1}{2}}}{i} \frac{A \exp \left\{i k\left(S_{0}+u^{3}\right)\right\}}{g^{\frac{1}{4}}} .
$$

We determine $S_{0}$ in such a way that on the shadow boundary

$$
\tilde{\varphi}_{\mathrm{inc}}=\exp \left\{i k\left(S_{0}+u^{3}\right)\right\} .
$$

This can always be done.

Hence we have

$$
A=\frac{i}{4 \pi^{\frac{1}{2}}} g^{\frac{1}{4}}
$$

and the asymptotic solution near the shadow boundary is

$$
\begin{aligned}
& \tilde{\varphi}_{d} \approx \frac{i}{4 \pi^{\frac{1}{2}}} g^{\frac{1}{4}} \frac{\exp \left\{i k\left(S_{0}+u^{3}\right)-i \frac{2}{3} p^{\frac{3}{2}}\right\}}{\left\{g^{\frac{1}{2}}+\left(u^{3}-u^{1}\right) \frac{\partial g^{\frac{1}{2}}}{\partial u^{1}}\right\}^{\frac{1}{2}}} \times \\
& \times \int_{C} e^{i t q}\left\{w_{2}(t-p)-\frac{w_{2}(t)}{w_{1}(t)} w_{1}(t-p)\right\} d t
\end{aligned}
$$


where

$$
\begin{aligned}
& p=\left(\frac{k}{2}\right)^{\frac{2}{3}} \varrho^{-\frac{4}{3}}\left\{h\left(u^{2}\right), u^{2}\right\}\left(u^{3}-u^{1}\right)^{2}, \\
& q=\left(\frac{k}{2}\right)^{\frac{1}{3}} \varrho^{-\frac{2}{3}}\left\{h\left(u^{2}\right), u^{2}\right\}\left[u^{1}-h\left(u^{2}\right)\right] .
\end{aligned}
$$

Writing $(12,2)$ as a sum of residues we find

$$
\begin{aligned}
& \tilde{\varphi}_{d} \approx-i \pi^{\frac{1}{2}} g^{\frac{1}{4}} \frac{\exp \left\{i k\left(S_{0}+u^{3}\right)-i^{\frac{2}{3}} p^{\frac{3}{2}}\right\}}{\left\{g^{\frac{1}{2}}+\left(u^{3}-u^{1}\right) \frac{\partial g^{\frac{1}{2}}}{\partial u^{1}}\right\}^{\frac{1}{2}}} \times \\
& \times \sum_{s=0}^{\infty} e^{i t_{s} q} \frac{w_{1}\left(t_{s}-p\right)}{\left\{w_{1}^{\prime}\left(t_{s}\right)\right\}^{2}}
\end{aligned}
$$

bearing in mind that $w_{1}\left(t_{s}\right)=0$.

At finite distance from the object we expand the Airy function for large values of $p$ and we get

$$
\begin{aligned}
& \tilde{\varphi}_{d} \approx \frac{\left(\frac{k}{2}\right)^{-\frac{1}{6}} \pi^{\frac{1}{2}} \varrho^{\frac{1}{3}}\left\{h\left(u^{2}\right), u^{2}\right\} g^{\frac{1}{4}}}{\left[\left(u^{3}-u^{1}\right)\left\{g^{\frac{1}{2}}+\left(u^{3}-u^{1}\right) \frac{\partial g^{\frac{1}{2}}}{\partial u^{1}}\right\}\right]^{\frac{1}{2}}} \exp \left\{i k\left(S_{0}+u^{3}\right)+\frac{\pi i}{4}\right\} \times \\
& \times \sum_{s=0}^{\infty} \frac{\exp \left\{i\left(\frac{k}{2}\right)^{\frac{1}{3}} \varrho^{-\frac{2}{3}}\left\{h\left(u^{2}\right), u^{2}\right\} t_{s}\left[u^{1}-h\left(u^{2}\right)\right]\right\}}{\left\{w_{1}^{\prime}\left(t_{s}\right)\right\}^{2}} .
\end{aligned}
$$

This solution is valid near the shadow boundary.

Because of the exponential behaviour of solution $(12,3)$ we assume, that at finite distance from this shadow boundary the exponential behaviour of the solution is [12]

$$
\exp \left\{i k\left(S_{0}+u^{3}\right)+i\left(\frac{k}{2}\right)^{\frac{1}{3}} t_{s} \int_{h\left(u^{2}\right)}^{u^{\prime}} \varrho^{-\frac{2}{3}}\left(u^{1}, u^{2}\right) \mathrm{d} u^{1}\right\}
$$

we are able to derive a solution in that region. We introduce the variable

$$
\gamma=\varrho^{-\frac{2}{3}} k^{\frac{1}{3}}\left(u^{3}-u^{1}\right)
$$

and the solution of the form

$$
\tilde{\varphi}_{d}=\sum_{s=0}^{\infty} \exp \left\{i k\left(S_{0}+u^{3}\right)+i\left(\frac{k}{2}\right)^{\frac{1}{3}} t_{s} \int_{h\left(u^{2}\right)}^{u^{1}} \varrho^{-\frac{2}{3}}\left(u^{1}, u^{2}\right) \mathrm{d} u^{1}\right\} \psi_{s}\left(u^{1}, u^{2}, \gamma\right) .
$$


Again we assume that each $\psi_{s}$ can be expanded as an asymptotic series of the form

$$
\psi_{s}=k^{r_{6}} \sum_{n=0}^{\infty} k^{-\frac{n}{3}} \psi_{n s}
$$

If we put this in equation $(11,9)$ and equate the coefficient of the highest power of $k$ to zero we get the ordinary differential equation for $\varphi_{0 s}$

$$
\frac{1}{\gamma^{2}} \frac{\partial^{2} \psi_{0 s}}{\partial \gamma^{2}}+\frac{\partial \psi_{0 s}}{\partial \gamma}\left\{-\frac{1}{\gamma^{3}}-\frac{2 i t_{s}}{\gamma^{2}}+2 i\right\}+\psi_{0 s}\left\{\frac{i t_{s}}{\gamma^{3}}-\frac{t_{s}^{2}}{\gamma^{2}}+\frac{i}{\gamma}\right\}=0
$$

with the solution

where

$$
\psi_{0 s}=\exp \left\{i\left(t_{s} \gamma-\frac{1}{3} \gamma^{3}\right)\right\} w_{1}\left(t_{s}-p\right) H\left(u^{1}, u^{2}, s\right)
$$

$$
p=2^{-\frac{2}{3}} \gamma^{2} \text {. }
$$

The asymptotic solution we have found has the form

$$
\begin{aligned}
\tilde{\varphi}_{d} & \approx k^{r_{6}} \sum_{s=0}^{\infty} \exp \left\{i k\left(S_{0}+u^{3}\right)+i\left(\frac{k}{2}\right)^{\frac{1}{3}} t_{s} \int_{h\left(u^{2}\right)}^{u^{1}} \varrho^{-\frac{2}{3}}\left(u^{1}, u^{2}\right) \mathrm{d} u^{1}+\right. \\
& \left.+i\left(t_{s} \gamma-\frac{1}{3} \gamma^{3}\right)\right\} w_{1}\left(t_{s}-p\right) H\left(u^{1}, u^{2}, s\right)
\end{aligned}
$$

We continue this solution at finite distance from the object and match it with $(12,3)$. This matching leads to $H\left(u^{1}, u^{2}, s\right)$ and $r_{6}$. After some calculations we find, at finite distance from the object,

$$
\begin{aligned}
& \tilde{\varphi}_{d} \approx \frac{\left(\frac{k}{2}\right)^{-\frac{1}{6}} \pi^{\frac{1}{2}} \varrho^{\frac{1}{3}}\left(u^{1}, u^{2}\right) g^{\frac{1}{4}}}{\left[\left(u^{3}-u^{1}\right)\left\{g^{\frac{1}{2}}+\left(u^{3}-u^{1}\right) \frac{\partial g^{\frac{1}{2}}}{\partial u^{1}}\right\}\right]^{\frac{1}{2}}} \exp \left\{i k\left(S_{0}+u^{3}\right)+\frac{\pi i}{4}\right\} \times \\
& \times \sum_{s=0}^{\infty} \frac{\exp \left\{i\left(\frac{k}{2}\right)^{\frac{1}{3}} t_{s} \int_{h\left(u^{2}\right)}^{u^{1}} \varrho^{-\frac{2}{3}}\left(u^{1}, u^{2}\right) \mathrm{d} u^{1}\right\}}{\left\{w_{1}^{\prime}\left(t_{s}\right)\right\}^{2}}
\end{aligned}
$$

and near the object

$$
\tilde{\varphi}_{d} \approx \frac{\pi^{\frac{1}{2}} g^{\frac{1}{4}} \exp \left\{i k\left(S_{0}+u^{3}\right)-i \frac{2}{3} p^{\frac{3}{3}}\right\}}{\left\{g^{\frac{1}{2}}+\left(u^{3}-u^{1}\right) \frac{\partial g^{\frac{1}{2}}}{\partial u^{1}}\right\}^{\frac{1}{2}}} \sum_{s=0}^{\infty} e^{i t_{s} q} \frac{w_{1}\left(t_{s}-p\right)}{\left\{w_{1}^{\prime}\left(t_{s}\right)\right\}^{2}}
$$


with

$$
\begin{aligned}
& p=\left(\frac{k}{2}\right)^{\frac{2}{3}} \varrho^{-\frac{4}{3}}\left(u^{3}-u^{1}\right)^{2}, \\
& q=\left(\frac{k}{2}\right)^{\frac{1}{3}}\left\{\int_{h\left(u^{2}\right)}^{u^{1}} \varrho^{-\frac{2}{3}}\left(u^{1}, u^{2}\right) \mathrm{d} u^{1}+\varrho^{-\frac{2}{3}}\left(u^{3}-u^{1}\right)\right\}
\end{aligned}
$$

All these solutions are singular in the points

$$
g^{\frac{1}{2}}+\left(u^{3}-u^{1}\right) \frac{\partial g^{\frac{1}{2}}}{\partial u^{1}}=0
$$

Therefore all the derived solutions are valid at finite distance from these singularities which we call the caustic points. It is possible, in principle, to apply the same method of boundary layer expansions to construct an asymptotic solution near these caustics D. LuDwig [2] discussed the behaviour of the field near the caustic in the general case. We therefore give no expansion by means of the boundary layer theory.

We are now able to give the complete solution in the shadow region at finite distance from the caustic. We must sum up all ray contributions. This is a geometrical problem which will not be solved here.

The solution in the lit region can be found in the same way as in the case of diffraction by a sphere. At finite distance from the shadow boundary we get the incident wave, the reflected wave and the diffracted wave. The latter is generated by the creeping rays and has been discussed before.

\section{THE INCIDENT WAVE IS SPHERICAL}

Remembering that the geometry which we consider depends on the incident wave, it is obvious, though the object is the same as the one of section 12, that the coordinate system which we introduce here is different. However, we use the same notation.

We now take as a solution of $(11,9)$ the form

$$
\chi=A \int_{C} e^{i t\left(q-q_{0}\right)} w_{1}\left(t-p_{0}\right)\left(v(t-p)-\frac{v(t)}{w_{1}(t)} w_{1}(t-p)\right) \mathrm{d} t
$$

where $p_{0}, q_{0}$ are the $p, q$ coordinates of the source. The shadow boundary on the object is called $u^{1}=h\left(u^{2}\right)$ and as we mentioned in section 12

$$
\varrho_{1}=\frac{g^{\frac{1}{2}}}{\frac{\partial g^{\frac{1}{2}}}{\partial u^{1}}}
$$


is the distance from a point on the shadow boundary $\left\{h\left(u^{2}\right), u^{2}\right\}$ to the source. We take the origin of $u^{3}$ in the source, so $S_{0}=0$.

Along the diffracted ray the arclength is $u^{3}-u^{1}$. We can derive the function $u^{1}=h\left(u^{2}\right)$ by eliminating $u^{1}$ from

$$
u^{1}=\frac{g^{\frac{1}{2}}}{\frac{\partial g^{\frac{1}{2}}}{\partial u^{1}}}
$$

As a solution in the shadow region near the shadow boundary we have

$$
\begin{aligned}
& \tilde{\varphi}_{d} \approx \frac{A k^{r_{7}} \exp \left\{i k u^{3}-i_{3}^{2}\left(p^{\frac{3}{2}}+p_{0}^{\frac{3}{2}}\right)\right\}}{\left\{\frac{g^{\frac{1}{2}}}{\partial g^{\frac{1}{2}}}+\left(u^{3}-u^{1}\right)\right)^{\frac{1}{2}}} \times \\
& \times \int_{C} e^{i t\left(q-q_{0}\right)} w_{1}\left(t-p_{0}\right)\left\{v(t-p)-\frac{v(t)}{w_{1}(t)} w_{1}(t-p)\right\} \mathrm{d} t .
\end{aligned}
$$

This solution should be equal to $\tilde{\varphi}_{\text {inc }}$ on the shadow boundary at finite distance from the object. Hence we expand $(13,2)$ for large values of $p_{0}$ and $p$ and find

$$
\tilde{\varphi}_{d}=2 A k^{r_{7}} \pi^{\frac{1}{2}} \varrho^{\frac{1}{3}}\left\{h\left(u^{2}\right), u^{2}\right\}\left(\frac{k}{2}\right)^{-\frac{1}{6}} \frac{\exp \left(i k u^{3}+\frac{\pi i}{4}\right)}{u^{3}}=\tilde{\varphi}_{\text {inc }}=\frac{\exp \left(i k u^{3}\right)}{u^{3}}
$$

from which follows

$$
A=\frac{2^{-\frac{1}{6}} e^{-\frac{\pi i}{4}}}{2 \pi^{\frac{1}{2}}} \varrho^{-\frac{1}{3}}, r_{7}=\frac{1}{6}
$$

Considering the case that the source is at finite distance from the object and the observation point near the object, we expand the solution for large values of $p_{0}$. Because the observation point may be at finite distance from the shadow boundary we use the variables of $(12,7)$ and get the solution

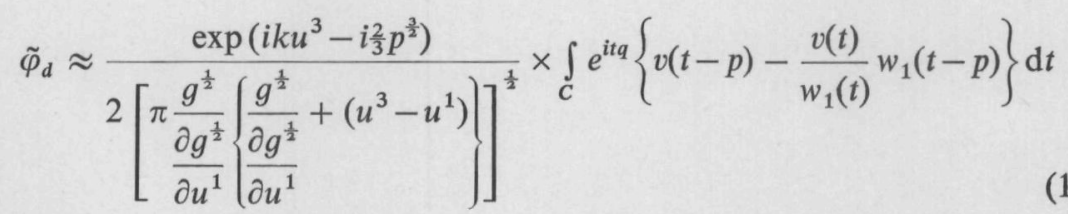


with

$$
\begin{aligned}
& p=\left(\frac{k}{2}\right)^{\frac{2}{3}} \varrho^{-\frac{4}{3}}\left(u^{3}-u^{1}\right)^{2} \\
& q=\left(\frac{k}{2}\right)^{\frac{1}{3}}\left\{\int_{h\left(u^{2}\right)}^{u^{1}} \varrho^{-\frac{2}{3}}\left(u^{1}, u^{2}\right) \mathrm{d} u^{1}+\varrho^{-\frac{2}{3}}\left(u^{3}-u^{1}\right)\right\}
\end{aligned}
$$

This solution can be expressed as a sum of residues in the region where this sum is rapidly convergent and we get

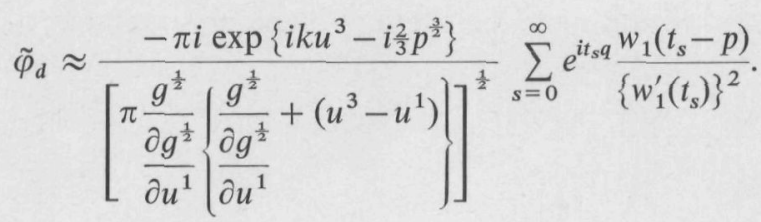

A solution at finite distance from the object will be gained by expanding $w_{1}\left(t_{s}-p\right)$ for large values of $p$

$$
\begin{aligned}
& \tilde{\varphi}_{d} \approx \frac{\left(\frac{k}{2}\right)^{-\frac{1}{6}} \pi^{\frac{1}{2}} \varrho^{\frac{1}{3}}\left(u^{1}, u^{2}\right) \exp \left(i k u^{3}-\frac{\pi i}{4}\right)}{\left[\frac{g^{\frac{1}{2}}}{\partial g^{\frac{1}{2}}}\left(u^{3}-u^{1}\right)\left\{\frac{g^{\frac{1}{2}}}{\partial u^{1}}+\left(u^{3}-u^{1}\right)\right]\right]^{\frac{1}{2}}} \times \\
& \times \sum_{s=0}^{\infty} \frac{\exp \left\{i\left(\frac{k}{2}\right)^{\frac{1}{3}} t_{s} \int_{h\left(u^{2}\right)}^{u^{1}} \varrho^{-\frac{2}{3}}\left(u^{1}, u^{2}\right) \mathrm{d} u^{1}\right\}}{\left\{w_{1}^{\prime}\left(t_{s}\right)\right\}^{2}}
\end{aligned}
$$

The final solution is a superposition of all ray contributions in the point of observation. It is not possible to write down this solution in a general form, but we can construct it for each geometry. In the lit region there is a superposition of the incoming, reflected and diffracted ray.

As we mentioned before special attention should be given to the behaviour in the neighbourhood of the caustic. In the next chapter we meet two problems without a caustic line or surface. 


\section{EXAMPLES}

\section{CIRCULAR CYLINDER WITH PLANE INCIDENT WAVE}

As an example of the general method given in Chapter III we will consider a circular cylinder in the field of a plane incident wave. The incident wave comes in with an angle $v$ with the axis of the cylinder. If $v=0$, we are dealing with the two-dimenional case. We must pay special attention to the radiation condition. The diffracted field at infinity will behave like the field of a line source; this can easily be shown by means of the theory of Green's functions and therefore the field behaves like $r^{-\frac{1}{2}}$ instead of $r^{-1}$ which appears in the case of diffraction around a closed finite obstacle.

We treat a circular cylinder with unit radius and a plane incoming wave with an angle of incidence equal to $v$. We take the axis of the cylinder along the $x^{3}$-axis and the incident rays parallel to the $x^{1} o x^{3}$ plane.

We introduce the coordinates $u^{1}, u^{2}, u^{3}$ as shown in Fig. 6

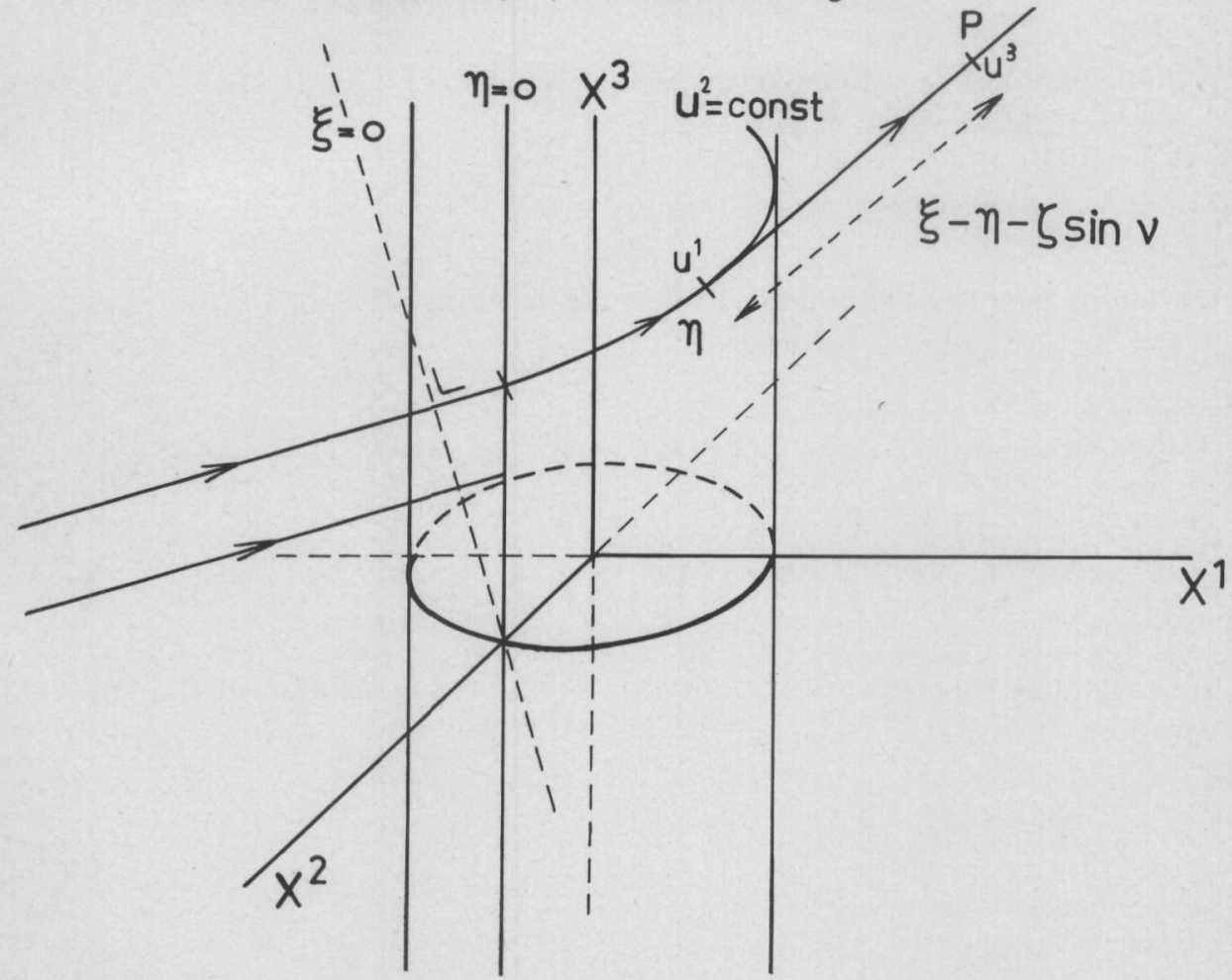

Fig. 6 


$$
\begin{array}{ll}
u^{1} & \text { is the arclength along the geodesic; } \\
u^{1}=0 & \text { is the shadow boundary on the cylinder; } \\
u^{2}=\text { constant } & \text { is the geodesic; } \\
u^{3} & \text { is the arclength along the ray. }
\end{array}
$$

A point $\mathrm{P}$ is determined by the values of $u^{i}$. These coordinates can easily be changed into other coordinates which in $\mathrm{P}$ will give an orthogonal coordinate system. We take analogous to the diffraction of a wave around a sphere the coordinate system

$$
\begin{aligned}
& u^{1}=\eta \\
& u^{2}=\zeta \\
& u^{3}=\xi-\eta-\zeta \sin v
\end{aligned}
$$

and in a point on the ray the line element $\mathrm{d} s$ is given by

$$
d s^{2}=d \xi^{2}+\left\{\frac{\xi-\eta-\zeta \sin v}{\varrho}\right\}^{2} d \eta^{2}+\cos ^{2} v d \zeta^{2}
$$

with the radius of curvature $\varrho$ of the geodesic equal to $1 / \cos ^{2} v$,

The incident wave will be given by

$$
\tilde{\varphi}_{\mathrm{inc}}=\exp \left\{i k\left(x^{1} \cos v+x^{3} \sin v\right)\right\} \text {. }
$$

Obviously the diffracted field depends on the incoming wave on $u^{1}=0$.

The Laplace operator becomes

$$
\begin{aligned}
\Delta & =\frac{\varrho}{\xi-\eta-\zeta \sin v}\left\{\frac{\partial}{\partial \xi}\left(\frac{\xi-\eta-\zeta \sin v}{\varrho}\right) \frac{\partial}{\partial \xi}+\frac{\partial}{\partial \eta}\left(\frac{\varrho}{\xi-\eta-\zeta \sin v}\right) \frac{\partial}{\partial \eta}+\right. \\
& \left.+\frac{1}{\varrho \cos ^{2} v} \frac{\partial}{\partial \zeta}(\xi-\eta-\zeta \sin v) \frac{\partial}{\partial \zeta}\right\} .
\end{aligned}
$$

We are interested in the wave function $\tilde{\varphi}_{d}$ which is a solution of the Helmholtz equation

$$
\Delta \tilde{\varphi}_{d}+k^{2} \tilde{\varphi}_{d}=0
$$

with boundary condition

$$
\tilde{\varphi}_{d}=0 \text { on the cylinder. }
$$


At infinity we require the behaviour of the complete field to be asymptotically equal to $\tilde{\varphi}_{\text {inc }}$ which in this case is a plane wave. The difference between the non-disturbed incoming wave and the diffracted wave solution behaves at infinity like $r^{-\frac{1}{2}}$ where $r$ means the distance to the axis of the cylinder. In particular we consider the field in the geometric shadow of the cylinder. The differential equation in the coordinates $\xi, \eta, \zeta$ and the solution of the form

$$
\tilde{\varphi}_{d}=\varphi_{d} e^{i k \xi}
$$

becomes

$$
\begin{aligned}
& \frac{1}{\xi-\eta-\zeta \sin v} \frac{\partial}{\partial \xi}(\xi-\eta-\zeta \sin v) \frac{\partial \varphi_{d}}{\partial \xi}+\frac{\varrho^{2}}{\xi-\eta-\zeta \sin v} \times \\
& \times \frac{\partial}{\partial \eta} \frac{1}{\xi-\eta-\zeta \sin v} \frac{\partial \varphi_{d}}{\partial \eta}+\frac{1}{\cos ^{2} v(\xi-\eta-\zeta \sin v)} \frac{\partial}{\partial \zeta}(\xi-\eta-\zeta \sin v) \frac{\partial \varphi_{d}}{\partial \zeta}+ \\
& +i k\left(2 \frac{\partial \varphi_{d}}{\partial \xi}+\frac{\varphi_{d}}{\xi-\eta-\zeta \sin v}\right)=0
\end{aligned}
$$

For large values of $k$ we find an asymptotic solution for $\varphi_{d}$ of the form

$$
\varphi_{d} \approx \frac{A(\eta, \zeta)}{(\xi-\eta-\zeta \sin v)^{\frac{1}{2}}}
$$

This solution is useful in the far region in the shadow and can be extended like $(2,12)$, however, it is singular near the cylinder. The complete solution in the shadow region can be found by considering the field near the shadow boundary and the cylinder. We introduce the coordinates

$$
\begin{aligned}
& \alpha=k^{\frac{1}{3}} \varrho^{-\frac{2}{3}}(\xi-\zeta \sin v), \\
& \beta=k^{\frac{1}{3}} \varrho^{-\frac{2}{3}} \eta, \zeta=\zeta .
\end{aligned}
$$

The differential equation which we get by equating the coefficient of the highest power of $k$ equal to zero, becomes

$$
\frac{1}{\alpha-\beta} \frac{\partial}{\partial \beta} \frac{1}{\alpha-\beta} \frac{\partial \varphi_{d}}{\partial \beta}+2 i \frac{\partial \varphi_{d}}{\partial \alpha}+\frac{i \varphi_{d}}{\alpha-\beta}=0
$$

with boundary condition

$$
\varphi_{d}=0 \quad \text { on the cylinder } \alpha=\beta
$$

and at finite distance from the cylinder

$$
\tilde{\varphi}_{d} \approx \tilde{\varphi}_{\mathrm{inc}} .
$$


The solution is of the form

with

$$
\tilde{\varphi}_{d} \approx \frac{i}{4 \pi^{\frac{1}{2}}} \exp \left(i k \xi-i \frac{2}{3} p^{\frac{3}{2}}\right) \int_{C} e^{i t q}\left\{w_{2}(t-p)-\frac{w_{2}(t)}{w_{1}(t)} w_{1}(t-p)\right\} \mathrm{d} t
$$

$$
\begin{array}{ll}
p=2^{-\frac{2}{3}}(\alpha-\beta)^{2} & =\left(\frac{k}{2}\right)^{\frac{2}{3}} \varrho^{-\frac{4}{3}}(\xi-\eta-\zeta \sin v)^{2} \\
q=2^{-\frac{1}{3}} \alpha & =\left(\frac{k}{2}\right)^{\frac{1}{3}} \varrho^{-\frac{2}{3}}(\xi-\zeta \sin v)
\end{array}
$$

This solution $(14,3)$ is the solution at large distance from the cylinder as well, because it behaves like $(14,2)$ for large values of $\xi-\eta-\zeta \sin v$.

Near the cylinder in the shadow region we get the solution

$$
\tilde{\varphi}_{d} \approx \frac{1}{\pi^{\frac{1}{2}}} \exp \left(i k \xi-i \frac{2}{3} p^{\frac{3}{2}}\right) \sum_{s=0}^{\infty} e^{i t_{s} q} \frac{w_{1}\left(t_{s}-p\right)}{\left\{w_{1}^{\prime}\left(t_{s}\right)\right\}^{2}}
$$

and for large values of $p$ we arrive at the solution by inserting the asymptotic behaviour of the Airy function. This solution is valid at finite distance from the shadow boundary where the series is rapidly convergent.

To find the complete solution in the shadow region we put all ray contributions together. Obviously this solution is nowhere singular in the shadow region, hence there is no caustic. The solution in the lit region can be developed in the same way as in the preceding sections.

\section{CIRCULAR CYLINDER WITH SPHERICAL INCIDENT WAVE}

As a second example we treat the diffraction of a spherical wave by a circular cylinder.

As we stated in Chapter III the main problem is to find a useful coordinate system because it is dependent on the incoming wave and the geometry of the object.

We consider a circular cylinder with radius one and a source at a distance from the axis of the cylinder equal to $\left(R^{2}+1\right)^{\frac{1}{2}}$.

The distance from the source to the shadow boundary on the cylinder is equal to $R / \cos v$. The arclength along the creeping ray we call $\eta$ and the arclength along the diffracted ray is equal to $\xi-\eta-R / \cos v$. So a point $\mathrm{P}$ is determined by $\xi, \eta$ and $v$ (Fig. 7). Of course this point is reached by an infinite amount of rays. We therefore have to add up all these contributions. We will now treat one of the rays.

With this choice of coordinates we have in point $\mathrm{P}$ the line element

$$
d s^{2}=d \xi^{2}+\left(\frac{\xi-\eta-\frac{R}{\cos v}}{\varrho(v)}\right)^{2} d \eta^{2}+\xi^{2} d v^{2}
$$




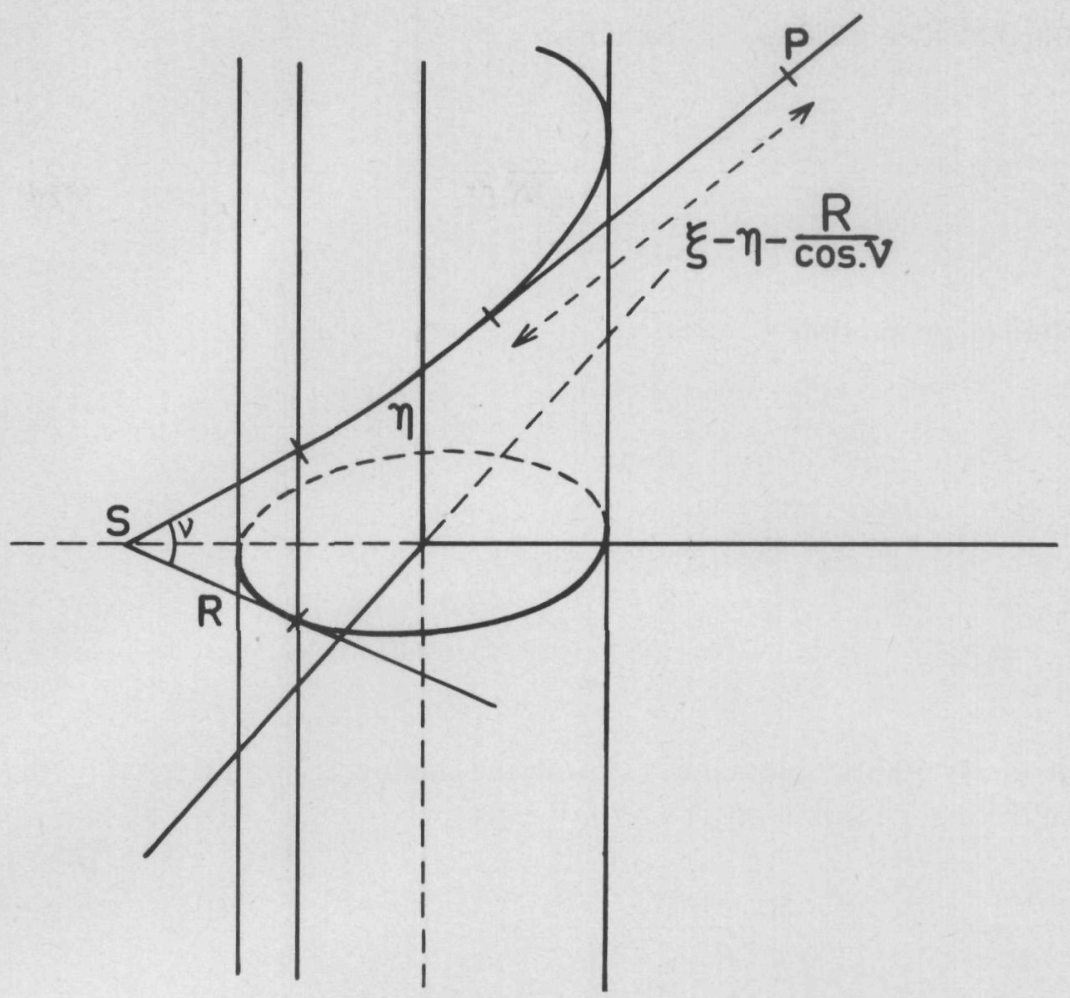

Fig. 7

with

$$
\varrho(v)=\frac{1}{\cos ^{2} v}
$$

and the Laplace operator becomes

$$
\left.\begin{array}{rl}
\Delta & =\frac{\varrho}{\xi\left(\xi-\eta-\frac{R}{\cos v}\right)}\left\{\frac{\partial}{\partial \xi} \frac{\xi\left(\xi-\eta-\frac{R}{\cos v}\right)}{\frac{\partial}{\partial \xi}+}\right. \\
+\frac{\partial}{\partial \eta} \frac{\varrho \xi}{\xi-\eta-\frac{R}{\cos v}} \frac{\partial}{\partial \eta}+\frac{\partial}{\partial v} \frac{\xi-\eta-\frac{R}{\cos v}}{\varrho \xi} \frac{\partial}{\partial v}
\end{array}\right\}
$$

We are looking for a solution of the Helmholtz equation of the form

$$
\tilde{\varphi}_{d}=\varphi_{d} e^{i k \xi}
$$


The differential equation for $\varphi_{d}$ becomes

$$
\Delta \varphi_{d}+i k\left\{2 \frac{\partial \varphi_{d}}{\partial \xi}+\frac{\varphi_{d}}{\xi\left(\xi-\eta-\frac{R}{\cos v}\right)} \frac{\partial}{\partial \xi} \xi\left(\xi-\eta-\frac{R}{\cos v}\right)\right\}=0
$$

with boundary condition

$$
\varphi_{d}=0 \text { for } \xi=\eta+\frac{R}{\cos v}
$$

and on the shadow boundary at finite distance from the cylinder

$$
\tilde{\varphi}_{d}=\tilde{\varphi}_{\mathrm{inc}}=\frac{e^{i k \xi}}{\xi}
$$

We get an asymptotic solution of $(15,1)$ in the shadow region by equating the coefficient of the highest power of $k$ to zero. We get

$$
\tilde{\varphi}_{d} \approx \frac{e^{i k \xi} A(\eta, v)}{\left\{\xi\left(\xi-\eta-\frac{R}{\cos v}\right)\right\}^{\frac{1}{2}}} .
$$

This solution is singular on the cylinder where

$$
\xi=\eta+\frac{R}{\cos v}
$$

In order to find the solution near the cylinder in the shadow region we start with the construction of this solution near cylinder and shadow boundary, so we introduce the coordinates

$$
\begin{aligned}
& \alpha=k^{\frac{1}{3}}\left(\xi-\frac{R}{\cos v}\right), \\
& \beta=k^{\frac{1}{3}} \eta, \\
& v=v .
\end{aligned}
$$

We put this in equation $(15,1)$ and the asymptotic solution will be the solution of the equation we get by calculating the coefficient of the highest power of $k$ equal to zero. 
We get the equation

$$
\frac{\varrho^{2}}{\alpha-\beta} \frac{\partial}{\partial \beta} \frac{1}{\alpha-\beta} \frac{\partial \varphi_{d}}{\partial \beta}+2 i \frac{\partial \varphi_{d}}{\partial \alpha}+\frac{i \varphi_{d}}{\alpha-\beta}=0
$$

where

$$
\varrho=\frac{1}{\cos ^{2} v}
$$

with boundary condition $\varphi_{d}=0$ for $\alpha=\beta$ and condition $(15,2)$.

We now introduce

and

$$
\begin{aligned}
& p=2^{-\frac{2}{3}} \varrho^{-\frac{4}{3}}(\alpha-\beta)^{2}, \\
& q=2^{-\frac{1}{3}} \varrho^{-\frac{2}{3}} \alpha
\end{aligned}
$$

$$
\chi=\varphi_{d} \exp \left(i \frac{2}{3} p^{\frac{3}{2}}\right) .
$$

Then we arrive at the equation for $\chi$ of the form

$$
\frac{\partial^{2} \chi}{\partial p^{2}}+i \frac{\partial \chi}{\partial q}+p \chi=0
$$

with

$$
\chi=0 \text { for } p=0 \text { and condition }(15,2) \text {. }
$$

Referring to section 9 and 13 we find the solution which also holds at finite distance from the cylinder.

$$
\begin{aligned}
& \tilde{\varphi}_{d} \approx \frac{A(v) k^{r_{8}} \exp \left\{i k \xi-i \frac{2}{3}\left(p^{\frac{3}{2}}+p_{0}^{\frac{3}{2}}\right)\right\}}{\xi^{\frac{1}{2}}} \times \\
& \times \int_{C} e^{i t\left(q-q_{0}\right)} w_{1}\left(t-p_{0}\right)\left\{v(t-p)-\frac{v(t)}{w_{1}(t)} w_{1}(t-p)\right\} \mathrm{d} t
\end{aligned}
$$

where $p_{0}$ and $q_{0}$ are the coordinates of the source. Condition $(15,2)$ determines $A$ and $r_{8}$. We find

$$
r_{8}=\frac{1}{6}, \quad A(v)=\frac{2^{-\frac{1}{6}} e^{-\frac{\pi i}{4}}}{2 \pi^{\frac{1}{2}}} \varrho^{-\frac{1}{3}}(v) .
$$

Near the cylinder and the source at finite distance from the cylinder we get the solution 


$$
\tilde{\varphi}_{d} \approx \frac{\exp \left(i k \xi-i \frac{2}{3} p^{\frac{3}{2}}\right)}{2\left(\pi \frac{R}{\cos v} \xi\right)^{\frac{1}{2}}} \times \int_{C} e^{i t q}\left\{v(t-p)-\frac{v(t)}{w_{1}(t)} w_{1}(t-p)\right\} \mathrm{d} t
$$

with

$$
\begin{aligned}
& p=\left(\frac{k}{2}\right)^{\frac{2}{3}} \varrho^{-\frac{4}{3}}(v)\left(\xi-\eta-\frac{R}{\cos v}\right)^{2}, \\
& q=\left(\frac{k}{2}\right)^{\frac{1}{3}} \varrho^{-\frac{2}{3}}(v)\left(\xi-\frac{R}{\cos v}\right)
\end{aligned}
$$

At finite distance from the shadow boundary we evaluate $(15,5)$ as a sum of residues and we arrive at

$$
\tilde{\varphi}_{d} \approx \frac{-\pi i \exp \left(i k \xi-i \frac{2}{3} p^{\frac{3}{2}}\right)}{\left(\pi \frac{R}{\cos v} \xi\right)^{\frac{1}{2}}} \sum_{s=0}^{\infty} e^{i t_{s} q} \frac{w_{1}\left(t_{s}-p\right)}{\left\{w_{1}^{\prime}\left(t_{s}\right)\right\}^{2}}
$$

Solution $(15,6)$ is also valid at finite distance from the shadow boundary. In the region far from the shadow boundary and the cylinder we must develop the Airy function $w_{1}$ for large values of $p$ which yields

$$
\tilde{\varphi}_{d} \approx \frac{\left(\frac{k}{2}\right)^{-\frac{1}{6}} \pi^{\frac{1}{2}} \varrho^{\frac{1}{3}}(v) \exp \left(i k \xi-\frac{\pi i}{4}\right)}{\left\{\frac{R}{\cos v} \xi\left(\xi-\eta-\frac{R}{\cos v}\right)\right\}^{\frac{1}{2}}} \sum_{s=0}^{\infty} \frac{\exp \left\{i\left(\frac{k}{2}\right)^{\frac{1}{3}} t_{s} \varrho^{-\frac{2}{3}}(v) \eta\right\}}{\left\{w_{1}^{\prime}\left(t_{s}\right)\right\}^{2}}
$$

The complete solution in the shadow region will be obtained by adding up all possible ray contributions. In the lit region we have to construct the solution just as we mentioned in the preceding sections.

In these two examples there were no caustic points. The only caustic was the source $\xi=0$ in section 15 , where the solution should be singular. 


\section{APPENDIX}

1. In our investigations extensive use is made of Airy functions. It is therefore appropriate to include a brief account of their properties and possible applications.

The integral

$$
v(t)=\frac{1}{\pi^{\frac{1}{2}}} \int_{0}^{\infty} \cos \left(\frac{x^{3}}{3}+x t\right) d x
$$

appeared in the research of AIRY (1838) "On the intensity of light in the neighbourhood of a caustic". STOKEs (1856) observed that this Airy integral represents one of the solutions of the differential equation

$$
w^{\prime \prime}(t)=t w(t)
$$

An other solution which is independent of (A1) is given by the integral

$$
w_{1}(t)=\frac{1}{\pi^{\frac{1}{2}}} \int \exp \left(t z-\frac{1}{3} z^{3}\right) \mathrm{d} z
$$

where the integration path $\Gamma$ in the complex $z$-plane runs from infinity to zero along the line $\operatorname{arc} z=-\frac{2}{3} \pi$ and from zero to infinity along the line $\operatorname{arc} z=0$. It can be proved that for real $t, w_{1}(t)$ can be separated in a real and an imaginary part

$$
w_{1}(t)=u(t)+i v(t)
$$

where $u(t)$ and $v(t)$ are independent solutions of (A2) and $v(t)$ given by (A1). The functions $u(t)$ and $v(t)$ are connected by the relation

$$
u^{\prime}(t) v(t)-u(t) v^{\prime}(t)=1 .
$$

These Airy functions are real for real values of $t$, but they are defined for all complex values of $t$ as well. In the complex $t$-plane the following relations hold [16, 17]

$$
\begin{aligned}
& w_{1}(t)=u(t)+i v(t)=2 e^{\frac{\pi i}{6}} v\left(t e^{\frac{2 \pi i}{3}}\right), \\
& w_{2}(t)=u(t)-i v(t)=2 e^{-\frac{\pi i}{6}} v\left(t e^{-\frac{2 \pi i}{3}}\right) .
\end{aligned}
$$


For large values of $|t|$ we find the asymptotic expansions

$$
v(t) \approx \frac{1}{2} t^{-\frac{1}{4}} \exp \left(-\frac{2}{3} t^{\frac{3}{2}}\right) \quad \text { if } \quad|\operatorname{arc} t|<\pi
$$

and for large negative values of $t$

$$
\begin{aligned}
& w_{1}(t) \approx(-t)^{-\frac{1}{4}} \exp \left\{i \frac{2}{3}(-t)^{\frac{3}{2}}+\frac{\pi i}{4}\right\} \\
& w_{2}(t) \approx(-t)^{-\frac{1}{4}} \exp \left\{-i \frac{2}{3}(-t)^{\frac{3}{2}}-\frac{\pi i}{4}\right\}
\end{aligned}
$$

These last two expansions are valid in the region

$$
-\frac{\pi}{3}<\operatorname{arc}(-t)<\frac{\pi}{3}
$$

2. We now investigate the asymptotic behaviour of the integral which appears in $(3,11)$

$$
J=\int_{C} e^{i t q}\left\{w_{2}(t-p)-\frac{w_{2}(t)}{w_{1}(t)} w_{1}(t-p)\right\} d t
$$

where the contour $C$ in the complex $t$-plane runs from infinity to zero along the line $\operatorname{arc} t=\frac{2}{3} \pi$ and from zero to infinity along the line arc $t=0$. We will give the asymptotic solution of $J$ for large values of $p$ and $q$ on the shadow boundary where $p=q^{2}$. We therefore apply the theory of steepest descent, which states that the largest distribution to the integral is given by the stationary point, if it lies on $C$. We therefore take $C$ through this stationary point, if any. We consider (A7) for large values of $p$ and $q$.

We notice that the stationary point becomes $t^{*}=p-q^{2}$ for both parts of the integral. In the dark region $t^{*}$ becomes negative on the shadow boundary $t^{*}=0$.

Considering the shadow region, we take the integration path $C$ through the point $t^{*}$. Near the shadow boundary $|t *|$ is small and if we consider the value of $J$ on the shadow boundary we find

$$
J \approx \frac{4 \pi^{\frac{1}{2}}}{i} \exp \left(i \frac{2}{3} p^{\frac{3}{2}}\right)
$$

In the shadow region at finite distance from the shadow boundary $t^{*}$ becomes large and negative, therefore we also develop $w_{2}(t) / w_{1}(t)$ for large negative values of $t$ and perform the method of steepest descent and we get the asymptotic result [16] 
with

$$
J \approx \frac{2 \pi^{\frac{1}{2}}}{i}\left[\exp \left\{i\left(p q-\frac{1}{3} q^{3}\right)\right\}-\left(\frac{1}{3}-\frac{2}{3} \frac{q}{\sigma}\right)^{\frac{1}{2}} \exp \left\{\frac{i}{27}\left(4 \sigma^{3}-3 \sigma^{2} q-2 q^{3}\right)\right\}\right]
$$

$$
\sigma=\left(q^{2}+3 p\right)^{\frac{1}{2}}
$$

3. In our treatment of the diffraction of a spherical wave we met integrals of the form

$$
\begin{aligned}
I & =\int_{C} e^{i t\left(q-q_{0}\right)} w_{1}\left(t-p_{0}\right)\left\{v(t-p)-\frac{v(t)}{w_{1}(t)} w_{1}(t-p)\right\} \mathrm{d} t= \\
& =\frac{i}{2} \int_{C} e^{i t\left(q-q_{0}\right)} w_{1}\left(t-p_{0}\right)\left\{w_{2}(t-p)-\frac{w_{2}(t)}{w_{1}(t)} w_{1}(t-p)\right\} \mathrm{d} t
\end{aligned}
$$

For large values of $p_{0}$ and $p$ we can use (A6) and determine the stationary point $t^{*}$. We find

$$
\begin{aligned}
& \left(p_{0}-t^{*}\right)^{\frac{1}{2}}=\mu+\frac{q-q_{0}}{2} \\
& \left(p-t^{*}\right)^{\frac{1}{2}}=\mu-\frac{q-q_{0}}{2}
\end{aligned}
$$

with

$$
\mu=\frac{p_{0}-p}{2\left(q-q_{0}\right)}
$$

and on the shadow boundary $t^{*}=0$.

If we transform the result into the $\xi, \eta$ coordinates, we find on the shadow boundary

$$
I \approx \frac{\left.2\left(\frac{k}{2}\right)^{-\frac{1}{6}} \pi^{\frac{1}{2}} e^{\frac{\pi i}{4}} \exp \left\{i_{3}^{2}\left(p^{\frac{3}{2}}+p_{0}\right)^{\frac{3}{2}}\right)\right\}}{\left(\operatorname{tg} \eta_{0}+\xi-\eta_{0}\right)^{\frac{1}{2}}}
$$

In the shadow region at finite distance from the shadow boundary we can also develop $w_{2}(t) / w_{1}(t)$ for large negative values of $t$ and perform the method of steepest descent again. 



\section{REFERENCES}

1. Nussenzveig, H. M., High-frequency scattering by an impenetrable sphere, Annals of Physics (1965), 34, 23.

2. LudwiG, D., Uniform asymptotic expansions at a caustic, Comm. Pure Appl. Math. (1966), $19,215$.

3. LudwiG, D., Uniform asymptotic expansions of the field scattered by a convex object at high frequencies, Comm. Pure Appl. Math. (1967), 20, 103.

4. Jones, D. S., Diffraction at high frequencies by a circular disc, Proc. Camb. Phil. Soc. (1965), $61,223$.

5. JONES, D. S., Diffraction of a high-frequency plane electromagnetic wave by a perfectly conducting circular disc, Proc. Camb. Phil. Soc. (1965), 61, 247.

6. Keller, J. B., Diffraction by a convex cylinder, I.R.E. Trans. Antennas Prop. (1956), AP-4, 312.

7. Keller, J. B., Diffraction by an aperture, J. Appl. Phys. (1957), 24, 426.

8. Levy, B. R. and J. B. Keller, Diffraction by a smooth object, Comm. Pure Appl. Math. (1959), $12,159$.

9. Keller, J. B., R. M. Lewis and B. D. SeCKLER, Asymptotic solution of some diffraction problems, Comm. Pure Appl. Math. (1956), 9, 207.

10. Buchal, R. N. and J. B. Keller, Boundary layer problems in diffraction theory, Comm. Pure Appl. Math. (1960), 13, 85.

11. Friedlander, F. G. and J. B. Keller, Asymptotic expansions of solutions of $\left(\nabla^{2}+k^{2}\right) u=0$, Comm. Pure Appl. Math. (1955), 8, 387.

12. ZAUDERER, E., Wave propagation around a smooth object, J. of Math. and Mech. (1964), 13, 187.

13. Grimshaw, R., High-frequency scattering by finite convex regions, Comm. Pure Appl. Math. (1966), 19, 167.

14. Lewis, R. M., N. Bleistein and D. Ludwig, Uniform asymptotic theory of creeping waves, Comm. Pure Appl. Math. (1967), 20, 295.

15. Hermans, A. J., The field of a spherical wave at high frequencies diffracted by a sphere, J. of Eng. Math. (1967), 1, 103.

16. Fock, V. A., Electromagnetic diffraction and propagation problems, Pergamon Press (1965).

17. Handbook of mathematical functions, Dover publ. (1965).

18. Landau, L. and E. Lifschitz, Physique theorique III, Theorie non relativiste, Editions Mir (1966), Moscou.

19. Kline, M. and J. W. KaY, Electromagnetic theory and geometrical optics, Interscience Publ. (1965).

20. Eisenhart, L. P., An introduction to differential geometry, Princeton University Press (1947). 


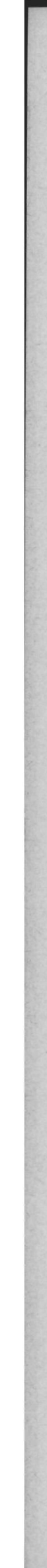




\section{STELLINGEN}

R. E. KLeINMAn geeft van de Helmholtz vergelijking

$$
\Phi_{x x}+\Phi_{y y}+k^{2} \Phi=0
$$

oplossingen van de vorm

$$
\Phi(x, y)=\frac{1}{2 i} \int_{x-i y}^{x+i y} J_{0}\left[k\left\{(x-\alpha)^{2}+y^{2}\right\}^{\frac{1}{2}}\right] \psi(\alpha) d \alpha,
$$

waarbij $\psi(\alpha)$ een analytische functie van de complexe variabele $\alpha$ is.

Het is mogelijk om van de diffusievergelijking

$$
F_{y y}+F_{z z}=k F_{x},
$$

zoals deze voorkomt bij de behandeling van transsone stromingen, oplossingen van soortgelijke vorm te geven, $\mathrm{nl}$.

$$
F(x, y, z)=2 \pi i \int_{K} \frac{d \beta}{x-\beta} \int_{y-i z}^{y+i z} \exp \left\{-k \frac{(y-\alpha)^{2}+z^{2}}{4(x-\beta)}\right\} \chi(\alpha, \beta) d \alpha,
$$

waarbij $\chi(\alpha, \beta)$ een analytische functie van de complexe variabelen $\alpha$ en $\beta$ is. De contour $K$ omvat het punt $\beta=x$. Indien in beide gevallen de normale afgeleide op een strip gegeven wordt, is het niet mogelijk om $\psi(\alpha)$ en $\chi(\alpha, \beta)$ zo te bepalen, dat aan alle fysische eisen voldaan is.

R. E. KLEINMAN. Integral representation of solutions of the Helmholtz equation and application to diffraction by a strip. T.H. Thesis.

R. Timman. Unsteady motion in transonic flow. Oswatitsch, Symposium Transonicum, 1963.

\section{II}

Bij de numerieke integratie van de partiële parabolische differentiaalvergelijking

$$
u_{t}=k u_{x x},
$$

met beginvoorwaarde

$$
u(x, 0)=\left\{\begin{array}{l}
0 \text { voor } x \neq 0 \\
1 \text { voor } x=0
\end{array}\right.
$$


kan men uitgaan van de differentievergelijking

met

$$
u_{n, m+1}-u_{n, m}=\alpha\left[\beta\left(\delta^{2} u\right)_{n}^{m+1}+(1-\beta)\left(\delta^{2} u\right)_{n}^{m}\right]
$$

en

$$
x=n \Delta x, t=m \Delta t, \alpha=\frac{k \Delta t}{(\Delta x)^{2}}
$$

Het ligt voor de hand om stabiliteit en convergentie van dit systeem te onderzoeken met behulp van de integraalvoorstelling

$$
u_{n, m}=\frac{1}{2 \pi i} \int_{c} z^{n-1} U_{m}(z) d z
$$

waarbij $C$ een contour is welke de singulariteiten van de integrand in het complexe $z$-vlak omvat.

\section{III}

Indien van de derde orde niet-lineaire partiële differentiaalvergelijking

$$
\frac{\partial}{\partial x} L(u)+\frac{\partial}{\partial t} M(u)=0
$$

met

$$
\begin{aligned}
& L(u)=a \frac{\partial^{2} u}{\partial x^{2}}+b \frac{\partial^{2} u}{\partial t^{2}}+V^{\prime}(u) \\
& M(u)=c \frac{\partial^{2} u}{\partial x^{2}}+d \frac{\partial^{2} u}{\partial t^{2}}+W^{\prime}(u)
\end{aligned}
$$

de functies $V(u)$ en $W(u)$ zo gekozen zijn, dat er een oplossing in de vorm van een uniforme golf mogelijk is, dan zijn er meer algemene oplossingen mogelijk in de vorm van langzaam variërende golven.

Verondersteld wordt, dat $u$ een functie is van de fase-functie $\theta(x, t)$ en de variabelen $X=\varepsilon x$ en $T=\varepsilon t$ en de vorm heeft:

$$
u(x, t)=U(\theta, X, T)+\varepsilon U_{1}(\theta, X, T)+\ldots .
$$

Analoog aan de beschouwingen van de tweede orde niet-lineaire differentiaalvergelijking door J. C. LuKe en H. W. Hoogstraten kunnen we $U$ oplossen en een dispersierelatie afleiden van de vorm

$\left(a \varkappa^{3}+b \varkappa \omega^{2}-c x^{2} \omega-d \omega^{3}\right) \oint[2\{B(X, T)-\varkappa V(U)+\omega W(U)+A(X, T) U\}]^{-\frac{1}{2}} d U=1$ met 


$$
\begin{aligned}
& \theta_{x}=x(X, T), \\
& \theta_{t}=-\omega(X, T) .
\end{aligned}
$$

Twee andere relaties om $\theta(x, t)$ en de integratie ,constanten" $A(X, T)$ en $B(X, T)$ te bepalen volgen uit de eis, dat $U_{1}(\theta, X, T)$ eindig moet zijn voor iedere $\theta, X$ en $T$. Hieruit volgt

$$
\int_{0}^{1} F(\theta, X, T) d \theta=0
$$

en

$$
\int_{0}^{1} U F(\theta, X, T) d \theta=0
$$

met $F(\theta, X, T)$ als een bekende relatie tussen $\theta, A$ en $B$. Uit (1), (2) en (3) kunnen $\theta$, $A$ en $B$ bepaald worden.

J. C. LUKE. A perturbation method for nonlinear dispersive wave problems. Proc. Roy. Soc. A, 292, (1966), 403.

H. W. Hoogstraten. Dispersion of non-linear shallow water waves. (To be published.)

IV

Het verband tussen de storingsmethode toegepast in stelling III en de variatiemethode van G. B. WнітнAм voor het bepalen van langzaam variërende golven is niet geheel duidelijk.

G. B. Whitham. Variational methods and applications to water waves. Proc. Roy. Soc. A, 299 (1967) pp. 6-25.

$$
\text { V }
$$

Onderzoekingen uitgevoerd door W. ECKHAUS en E. M. DE JAGER, welke er op gericht zijn bewijzen te leveren omtrent asymptotiek, dienen te worden uitgebreid tot een groter aantal praktische problemen.

W. ECKHAUS \& E. M. DE JAGER. Asymptotic solutions of singular perturbation problems for linear differential equations of elliptic type. Arch. of Rat. Mech. and An. 23 (1966) pp. 26-86.

VI

Bij de bepaling van vlakke golven op water met eindige diepte gaat T. H. HAVELOCK uit van enkele veronderstellingen omtrent golfvorm en golfopwekker. Het is mogelijk om zonder deze ,a priori” veronderstellingen oplossingen te vinden met behulp van Laplace transformaties. De resultaten zijn uiteraard identiek aan die welke door HAVELOCK gevonden zijn.

T. H. Havelock. Surface-waves on water. Phil. mag. 8 (1929) pp. 569-576, section 5 . 
De oplossingen, welke door J. B. KeLLeR langs intuïtieve weg gevonden zijn bij de behandeling van de diffractie om een convexe cilinder, kunnen afgeleid worden met behulp van de methoden welke in dit proefschrift behandeld zijn.

J. B. KeLLeR. Diffraction by a convex cylinder. I.R.E. Trans. Antennas. Prop. (1956), AP84,312.

\section{VIII}

De correctie, die J. B. KeLLER toepast om het veld in de omgeving van een axiale caustic te bepalen [ref. 40], geeft resultaten, welke asymptotisch in overeenstemming zijn met de resultaten zoals deze voor een soortgelijk probleem in hoofdstuk I en II afgeleid zijn. De resultaten van J. B. KeLLER kunnen niet direct afgeleid worden.

J. B. Keller. Diffraction by an aperture. J. Appl. Phys. (1957), 28, 426.

IX

Het is zinloos stellingen te poneren waarin een persoonlijke visie gegeven wordt over zaken, welke met het vakgebied van het proefschrift niet verwant zijn. 


\section{SAMENVATTING}

In dit proefschrift wordt een systematische behandeling van de asymptotische ontwikkeling van de drie-dimensionale Helmholtz-vergelijking $\Delta \tilde{\varphi}+k^{2} \tilde{\varphi}=0$ gegeven, waarbij de frequentie $k$ groot wordt verondersteld en onafhankelijk van de plaatscoördinaten. Behandeld wordt de verstrooiing van een gegeven inkomend veld door een convex lichaam zonder scherpe randen. Het geometrische schaduwgebied van dit lichaam wordt beschouwd.

Als randvoorwaarde nemen wij $\tilde{\varphi}=0$ op het lichaam en in het oneindige dient het veld aan de uitstralingsvoorwaarde te voldoen.

Om een asymptotische oplossing te vinden van de Helmholtz-vergelijking wordt gebruik gemaakt van de stralen-theorie. Hiertoe worden de begrippen 'straal' en 'creeping straal' ingevoerd. Deze begrippen voeren ons tot een bruikbaar coördinaten-systeem.

In hoofdstuk I wordt de verstrooiing van een vlakke inkomende golf door een eenheidsbol beschouwd. Met behulp van grenslaagbeschouwingen worden asymptotische differentiaalvergelijkingen in verschillende gebieden afgeleid en hiervoor worden oplossingen gezocht, welke voldoen aan de gegeven randvoorwaarde en de uitstralingsvoorwaarde, indien de beschouwde gebieden zich uitstrekken respectievelijk tot de bol en tot het oneindige.

Indien dit niet het geval is worden randvoorwaarden gevonden uit de eis dat de oplossingen in aan elkaar grenzende gebieden dienen aan te sluiten. Speciale aandacht moet in dit geval geschonken worden aan het veld in de buurt van de as van symmetrie, welke hier een caustische lijn blijkt te zijn. Ook in de nabijheid van deze lijn worden oplossingen gevonden.

In hoofdstuk II worden analoge beschouwingen gehouden voor het geval van verstrooiing van een sferische golf door een eenheidsbol.

In hoofdstuk III wordt, met behulp van differentiaalmeetkunde, in het schaduwgebied van een convex lichaam zonder scherpe randen een punt gegeven in 'straal'coördinaten. De Helmholtz-vergelijking wordt getransformeerd op deze coördinaten en in verschillende gebieden worden asymptotische oplossingen gegeven, welke bij elkaar aansluiten en voldoen aan de randvoorwaarde en uitstralingsvoorwaarde. Uit de behandeling volgt dat ook in dit algemene geval een caustisch oppervlak kan optreden. In principe kan in de buurt van dit caustisch oppervlak een oplossing geconstrueerd worden. In afzonderlijke gevallen kan dit overzichtelijke resultaten geven. In dit hoofdstuk wordt zowel de inkomende vlakke als de sferische golf behandeld. 
In hoofdstuk IV wordt de verstrooiing beschouwd van een vlakke golf door een cirkelcilinder onder een willekeurige invalshoek en tevens van een sferische golf door hetzelfde lichaam. In dit geval is er geen caustisch oppervlak aanwezig.

Tot slot volgt nog een appendix, waar enkele eigenschappen en ontwikkelingen van Airy-functies gememoreerd worden. 